\title{
Better Schools, Less Crime?
}

\section{Citation}

Deming, D. J. 2011. “Better Schools, Less Crime?” The Quarterly Journal of Economics 126 (4)

(November 1): 2063-2115. doi:10.1093/qje/qjr036. http://dx.doi.org/10.1093/qje/qjr036.

\section{Published Version}

10.1093/qje/qjr036

\section{Permanent link}

http://nrs.harvard.edu/urn-3:HUL.InstRepos:12308135

\section{Terms of Use}

This article was downloaded from Harvard University's DASH repository, and is made available under the terms and conditions applicable to Open Access Policy Articles, as set forth at http:// nrs.harvard.edu/urn-3:HUL.InstRepos:dash.current.terms-of-use\#OAP

\section{Share Your Story}

The Harvard community has made this article openly available.

Please share how this access benefits you. Submit a story.

Accessibility 


\title{
BETTER SCHOOLS, LESS CRIME?*
}

\author{
DAVID J. DEMING
}

I estimate the impact of attending a first-choice middle or high school on adult crime, using data from public school choice lotteries in Charlotte-Mecklenburg school district (CMS). Seven years after random assignment, lottery winners had been arrested for fewer serious crimes and had spent fewer days incarcerated. The gain in school quality as measured by peer and teacher inputs was equivalent to moving from one of the lowest-ranked schools to one at the district average. The reduction in crime comes largely from years after enrollment in the preferred school is complete. The impacts are concentrated among high-risk youth, who commit about 50\% less crime across several different outcome measures and scalings of crime by severity. I find suggestive evidence that school quality explains more of the impact in high school, whereas peer effects are more important in middle school. JEL Codes: I20, I21.

\section{INTRODUCTION}

Can improvement in the quality of public schools be an effective crime prevention strategy? Criminal activity begins in early adolescence and peaks when most youth should still be enrolled in secondary school (Farrington et al. 1986; Wolfgang, Figlio, and Sellin 1987; Levitt and Lochner 2001; Sampson and Laub 2003). Crime is concentrated among minority males from high-poverty neighborhoods (Freeman 1994; Pettit and Western 2004; Raphael and Sills 2007). An influential literature on "neighborhood effects" links criminal activity to neighborhood disadvantage through peer interaction models (Sah 1991; Glaeser, Sacerdote, and Scheinkman 1996) or processes of socialization and collective efficacy (Sampson, Raudenbush, and Earls 1997).

*I thank Lawrence Katz, Susan Dynarski, Brian Jacob, and Sandy Jencks for reading drafts and providing essential guidance and feedback. I benefited from the helpful comments of Josh Angrist, Amitabh Chandra, Roland Fryer, Alex Gelber, Josh Goodman, Bridget Long, Jens Ludwig, ErzoLuttmer, Juan Saavedra, Bruce Western, Tristan Zajonc, and seminar participants at the Center for Education Policy Research (CEPR) series at Harvard University, the Center for the Developing Child at Harvard University, and the University of Michigan. Special thanks to Tom Kane, Justine Hastings, and Doug Staiger for generously sharing their lottery data, and Eric Taylor and Andrew Baxter for help with matching the student and arrest record files. I gratefully acknowledge funding from the Julius B. Richmond Fellowship at the Center for the Developing Child and the Multidisciplinary Program on Inequality and Social Policy at Harvard.

(C) The Author(s) 2011. Published by Oxford University Press, on the behalf of President and Fellows of Harvard College. All rights reserved. For Permissions, please email: journals. permissions@oup.com.

The Quarterly Journal of Economics (2011) 126, 2063-2115. doi:10.1093/qje/qjr036.

Advance Access publication on October 19, 2011. 
Schools may be a particularly important setting for the onset of criminal behavior. ${ }^{1}$ Urban schools in high-poverty neighborhoods have high rates of violence and school dropout and struggle to retain effective teachers (Lankford, Loeb, and Wyckoff 2002; Murnane 2008; Cook, Gottfredson, and Na 2010). Only 35\% of inmates in U.S. correctional facilities earned a high school diploma or higher, compared with $82 \%$ of the general population (Harlow 2003). The best existing empirical evidence of the link between education and crime comes from Lochner and Moretti (2004), who use changes in compulsory schooling and child labor laws to estimate the effect of additional years of schooling on criminal activity. But the intensive margin of school quality is potentially more relevant for policy. In a human capital framework, lowskilled youth will engage in crime early in life because of low anticipated returns to schooling (Lochner 2004). If increased quality raises the return to investment in schooling, youth will stay in school longer, earn higher wages as adults, and commit fewer crimes. ${ }^{2}$ Yet there is little evidence of the effect of school quality on crime. ${ }^{3}$

In this article, I link a long and detailed panel of administrative data from Charlotte-Mecklenburg school district (CMS) to arrest and incarceration records from Mecklenburg County and the North Carolina Department of Corrections (NCDOC). In 2002, CMS implemented a district-wide open enrollment school choice plan. Slots at oversubscribed schools were allocated by random lottery. School choice in CMS was exceptionally broadbased. Ninety-five percent of students submitted at least one choice, and about $40 \%$ chose a nonguaranteed school. Youth at

1. Because most public schools' assignment zones are defined by neighborhood, disentangling the separate influences of neighborhoods and schools is difficult. Jacob and Lefgren (2003) find that contemporaneous school enrollment leads to decreases in property crime but increases in violent crime, although their sample is not representative of large urban school districts.

2. Additional compulsory schooling might accomplish the same goal, but the range of options for policy makers is limited. The minimum school leaving age is already 18 in 18 states, and enforcement of truancy laws is sporadic (Oreopoulos 2006). Also, the population of "never takers" (i.e., youth who would drop out of school at the same age regardless of the law) might be particularly important.

3. Economic models of crime focus largely on changes in costs and benefits of crime for individuals on the margin of work and criminal activity (Becker 1968; Ehrlich 1973; Grogger 1998; Freeman 1994). A notable exception is Lochner (2004), who examines the onset of criminal behavior in a life-cycle model of schooling, crime, and work. A recent paper by Weiner, Lutz, and Ludwig (2009) finds a significant decline in homicide following school desegregation. 
higher ex ante risk for crime were actually more likely to choose a nonguaranteed school, allaying concerns about "cream-skimming" that might complicate the external validity of the findings (Epple and Romano 1998).

I estimate the causal effect of winning the lottery to attend a first-choice school on criminal activity through 2009, 7 years after random assignment. Across various schools and for both middle and high school students, I find consistent evidence that winning the lottery reduces adult crime. ${ }^{4}$ The effect is concentrated among African American males and youth who are at highest risk for criminal involvement. Across several different outcome measures and scalings of crime by severity, high-risk youth who win the lottery commit about 50\% less crime. They are also more likely to remain enrolled and "on track" in school, and they show modest improvements on school-based behavioral outcomes such as absences and suspensions. However, there is no detectable impact on test scores for any youth in the sample.

Nearly all of the reduction in crime occurs after enrollment in the preferred school is complete. Differences between lottery winners and losers persist 4-7 years after random assignment in both the middle and high school samples. The changes in peer and teacher quality experienced by lottery winners are roughly equivalent in magnitude to moving from one of the worst schools in the district to a school of average quality. Because nearly all of the lottery applicants stayed in CMS, winners and losers attended schools with similar budgets and governance structures. There were no additional community-level interventions, such as in the Harlem Children's Zone (Dobbie and Fryer 2009). In sum, a treatment of between 1 and 4 years of enrollment in a higher quality public school led to large and persistent reductions in young adult criminal activity.

The pattern of results is consistent with at least two distinct explanations. Human capital theory predicts that offering youth admission to a better school would raise the return to investment in schooling, keeping them enrolled longer and increasing their opportunity cost of crime as adults (Lochner 2004). ${ }^{5}$ However, the results are also consistent with a model of peer influence where

4. Youth age 16 and above are considered "adult" by the criminal justice system in North Carolina. I do not observe juvenile crime.

5. This presumes that crime-prone youth are forward-looking and respond rationally to a higher return on schooling investment. However, Lee and McCrary (2005) find that youth in Florida do not respond to the discontinuous change in 
differential exposure to crime-prone youth exerts a long-lasting influence on adult crime. To test these different hypotheses, I perform some back-of-the-envelope calculations using the estimated changes in enrollment and exposure to crime-prone peers. I find suggestive evidence that the impacts in high school are more attributable to gains in school quality, whereas the results in middle school are driven more by peer effects. An important caveat, however, is that the lottery sample is self-selected. If highrisk lottery applicants are in the sample because they (or their families) are trying to escape the negative influence of particular peers in their neighborhood schools, the impact of winning the lottery could be driven by match-specific peer effects that would not show up in the calculations.

Each of these mechanisms has different implications for the aggregate effect of school choice on crime. If the impacts are driven by an improvement in school quality that is invariant to peer group composition, then a lottery that holds school size constant would have no aggregate effect on crime. As I discuss in Section V, however, CMS expanded capacity at highly demanded schools, and many neighborhood schools in the inner city lost a substantial share of enrollment. In that case, increased school quality would reduce crime absent any impact of changing peer composition.

I show that the net effect of school choice was to distribute high-risk youth more evenly across schools than what would have happened with neighborhood school assignment. Available evidence on the functional form of peer effects suggests that concentrations of high-risk youth increase the aggregate level of misbehavior, and I find some evidence of that pattern of peer effects in CMS middle schools (Cook and Ludwig 2005; Imberman, Kugler, and Sacerdote 2011; Carrell and Hoekstra 2010). Finally, since improvements in measured school quality and peer composition do not explain much of the impact of winning the lottery on crime, we might conclude that better matching of students to schools plays an important role. This is another channel through which school choice could be welfare-enhancing (Hoxby 2003). Though the balance of the evidence points toward school choice leading to a net reduction in crime, extrapolation from the direct effect on lottery applicants is speculative and should be viewed with caution.

expected punishment at the age of majority, suggesting that they are impatient, myopic, or both. 
I exploit the richness of prelottery administrative data and estimate the probability that a youth will be arrested in the future as a function of demographics, prior academic performance, behavior in school, and detailed neighborhood characteristics. The effect on crime of winning admission to a preferred school is strongly increasing in this ex ante prediction. Thus societal welfare gains from targeting resources to these youth might be substantial (Donohue and Siegelman 1998). Although random assignment of slots to oversubscribed schools is an ideal research design, it may be suboptimal from a welfare perspective if treatment effects can be predicted on the basis of observable characteristics (Bhattacharya and Dupas 2008). I simulate the effect of allocating slots based on ex ante crime risk rather than at random, and I find that this would reduce the social cost of crime by an additional $27 \%$. Although this allocation method is controversial (and in the case of race, illegal), it was executed at least in part by CMS, which gave a "priority boost" in the lottery to applicants who met an income standard based on eligibility for free or reduced-price school lunches. I estimate that this priority boost lowered crime by $12 \%$, relative to a lottery without priority groups such as the ones typically administered by U.S. charter schools.

Several recent papers have found large positive impacts on test scores of winning admission to an oversubscribed public or charter school using a lottery-based design (Hastings, Kane, and Staiger 2008; Hoxby and Murarka 2009; Angrist et al. 2010; Abdulkadiroglu et al. 2011; Dobbie and Fryer 2011). Although these short-term test score gains are promising, data limitations have prohibited examination of longer term outcomes measured outside the school setting.

There are at least two reasons we might want to look beyond test scores and other school-based measures. First, there is an emerging literature on the unintended consequences of test-based accountability, which range from neglect of nontested subjects to manipulation of the nutritional content of school lunches and outright teacher cheating (Jacob and Levitt 2003; Figlio and Winicki 2005; Jacob 2005; Figlio 2006). This leads to concerns that schools may raise student test scores through methods that do not translate to long-term improvements in skills or educational attainment. Second, even in the absence of distortionary incentives, the correlation between test score gains and improvements in long-term outcomes has not been conclusively established. Studies that relate test scores to earnings later in life, 
while suggestive, are not well-identified (Murnane, Willett, and Levy 1995; Jencks and Phillips 1999; Currie and Thomas 2001). Furthermore, studies of early life and school-age interventions often find long-term impacts on outcomes such as educational attainment, earnings and criminal activity, despite nonexistence or "fade out" of test score gains (Krueger and Whitmore 2001; Gould, Lavy, and Paserman 2004; Belfield et al. 2006; Kemple and Willner 2008; Deming 2009). Thus programs can yield longterm benefits without raising test scores, and test score gains are no guarantee that impacts will persist over time. Taken together, the results here and in other studies suggest that looking only at test score gains may miss important benefits of interventions, particularly for disadvantaged youth.

This article uses random assignment to examine the longer term impact of school choice on crime, an important adult outcome measured outside the school setting. The most similar study to this one is Cullen, Jacob, and Levitt (2006), who estimate the impact of winning an admissions lottery to attend a Chicago public high school on a variety of outcomes. They find no impact of school choice on test scores or graduation but some benefits on behavioral outcomes, including self-reported criminal activity and incarceration during the years in which a student is enrolled. ${ }^{6}$ This article improves on those findings in a number of ways. Most important, the results in Cullen, Jacob, and Levitt (2006) are based on selfreported arrests in a survey administered in ninth grade, just 9 months after lottery participants enroll in high school. Recent evidence from the Moving to Opportunity (MTO) Demonstration suggests that youth significantly underreport criminal activity and that the probability of under reporting might be positively correlated with treatment. ${ }^{7}$ Furthermore, even if under reporting is orthogonal to lottery status, differences in police presence and

6. Lavy (2010) studies public school choice in Tel Aviv using differences-indifferences and regression discontinuity methods, and finds evidence of a reduction in self-reported violence and classroom disruption.

7. In Kling, Ludwig, and Katz (2005), $29 \%$ of male youth in the control group and $30 \%$ in the treatment group self-report having ever been arrested, while the administrative data show rates of $39 \%$ and $44 \%$ for control and treatment males, respectively (Table IV). While the treatment-control reporting difference is not statistically significant, Kling, Ludwig, and Katz (2005) estimate that uniform under reporting of arrests can explain less than one-tenth of the treatmentcontrol difference (note 22). Here and in Cullen, Jacob, and Levitt (2006), lottery winners know their treatment status and may also be exposed to different norms of behavior in their chosen school. This raises concerns that lottery winners might be more likely than lottery losers to underreport their own criminal activity. 
tracking of student misbehavior across schools might complicate the interpretation of the findings in the first few years. ${ }^{8}$ I overcome these limitations by tracking detailed measures of criminal activity using administrative data, and for 7 years after random assignment, long after enrollment in the initial school is complete.

This article provides some evidence that schooling exerts a particularly strong influence on criminal behavior. The MTO Demonstration found mixed impacts on crime (Ludwig, Duncan, and Hirschfield 2001; Kling, Ludwig, and Katz 2005). In MTO, the male children of housing voucher recipients committed fewer violent crimes initially but more property crimes $3-4$ years after random assignment. Similarly, Jacob (2004) finds no independent impact on academic outcomes of moving out of high-density public housing. In contrast, the CMS open enrollment plan can be thought of as a pure school mobility experiment. In both MTO and the middle school sample here, there was no overall reduction in crime, only a substitution toward property crime and away from violent crime (along the intensive margin of crime severity).

In both settings, changing peer groups seemed to be the most important mechanism for reductions in violent crime, since gains in measured school quality were modest and reflected changing demographics (Sanbonmatsu et al. 2006). Why was there no longrun reduction in criminal behavior along the extensive margin? One potential explanation is that although changes in social setting can reduce violent crime by limiting interactions between high-risk youth, persistent reductions in criminality are difficult to achieve without affecting skills and/or employability. This is consistent with the pattern of results for high school lottery winners, where there was an overall reduction in arrests and more evidence of increases in (nonpeer) school quality. However, more research is needed to disentangle the relative contributions of neighborhoods and schools, and these conclusions are at best suggestive.

8. If, for example, the schools to which lottery applicants are assigned have more police in the school building or handle disciplinary incidents more strictly, winning the lottery to attend a "better" school might decrease the probability of being arrested conditional on the level of "true" criminal activity. In other words, the reduction in arrests is mechanical and not a true decline in criminal behavior. This is more likely to be true for some crimes than others (i.e., disorderly conduct versus armed robbery), but the survey in Cullen, Jacob, and Levitt (2006) only asks whether a student has been arrested in the past year, with no information on crime type. 


\section{DATA Description AND Institutional Details}

\section{II.A. Data}

With over 150,000 students enrolled in the 2008-2009 school year, CMS is the 20th largest school district in the nation. The CMS attendance area encompasses all of Mecklenburg County, including the entire city of Charlotte and several surrounding cities. Since the mid-1990s, the North Carolina Department of Public Instruction (NCDPI) has required all districts to submit a set of end-of-year (EOY) files that include demographic information, attendance and behavioral outcomes, yearly test scores in math and reading for grades 3 through 8 , and subject-specific tests for higher grades. Internal CMS files obtained under a data use agreement also include identifying information such as name and date of birth, and students' exact addresses in every year, which I use to create detailed geographic identifiers. For more details on the nature and quality of the CMS administrative data, see the Online Appendix.

I match CMS administrative data to arrest records from the Mecklenburg County Sheriff(MCS). ${ }^{9}$ I obtain these arrest records directly from the MCS website, which maintains an online searchable database that covers arrests in the county for the previous 3 years, counting from the day the website is accessed. ${ }^{10}$ The data include all arrests of adults (age 16 and over in North Carolina) that occurred in the county, even if they were handled by another agency. Arrestees are tracked across incidents using a unique identifier that is established with fingerprinting. Critically, each observation includes the name and date of birth of the criminal.

The match was done using name and date of birth and was exact in about $87 \%$ of cases. I obtained the remaining matches using an algorithm that assigns potential matches a score based on the number and nature of differences. ${ }^{11} \mathrm{I}$ investigated match

9. Because CMS is a unified school district, the geographic coverage of the school administrative data and the arrest records is identical.

10. The web address is http://arrestinquiryweb.co.mecklenburg.nc.us/. I obtained the data by writing a script that loops over arrest numbers in consecutive order and copies the relevant information into a text file. See the Online Appendix for details.

11. As a specification check I ran the partial match algorithm a number of different ways, and I also estimated all the results in the article using exact matches only. The results were almost identical. Also, to address concern that match quality might be correlated with subsequent school quality, I reran the match using only name and date of birth information that was available prior 
quality in several different ways, which are outlined in the Online Appendix. ${ }^{12}$ Since the CMS open enrollment plan began in 2002, some older members of the sample could have been arrested prior to 2006, when the arrest data begin. To address this issue, I also obtained historical arrest records directly from MCS for members of the lottery sample only. Finally, I add incarceration records from the MCS jail system and the North Carolina Department of Corrections (NCDOC). These county jail and state prison records are consistently available beginning only in 2006 , and they were collected only for African American male members of the lottery sample. ${ }^{13}$ The data include number of days incarcerated, but probation and parole records are not included. See the Online Appendix for more details on the collection and coding of the arrest and incarceration data.

\section{II.B. School Choice in Charlotte-Mecklenburg}

From 1971 until 2001, CMS schools were forcibly desegregated under a court order. Students were bused all around the district to preserve racial balance in schools. After several years of legal challenges, the court order was overturned, and CMS was instructed that it could no longer determine student assignments based on race. In December 2001 the CMS School Board voted on a policy of district-wide open enrollment for the 2002-2003 school year. School boundaries were redrawn as contiguous neighborhood zones, and children who lived in each zone received guaranteed access to their neighborhood school. The 1-year change in student assignments was dramatic-about $40 \%$ of students at the middle and high school level were assigned to a different school than in the previous year. Because the inner city of Charlotte is dense and highly segregated, African American and poor students were even more likely to be reassigned.

to the lottery. About 175 matches were lost with this restriction, but only 7 were in the lottery sample. The results were substantively unchanged. See the Online Appendix for details.

12. These steps include verifying that there are no large time gaps in the data, that the age and demographic profile of arrests fits other studies, and that a high percentage of arrests among age-appropriate youth in Mecklenburg County are successfully matched to CMS data. See the Online Appendix for details.

13. The data are limited to African American males because I was unable to automate the collection process as well as for the arrest data. See the Online Appendix for details. 
The open enrollment lottery took place in spring 2002. CMS conducted an extensive outreach campaign to ensure that choice was broad-based, and $95 \%$ of parents submitted at least one choice (Hastings, Kane, and Staiger 2008). Parents could submit up to three choices (not including their neighborhood school). Students were guaranteed access to their neighborhood school, and admission for all other students was subject to grade-specific capacity limits that were set by the district beforehand but were unknown to families at the time of the lottery (Hastings, Kane, and Staiger 2008). When demand for slots among nonguaranteed applicants exceeded supply, admission was allocated by random lotteries according to the following strictly ordered priority groups:

1. Students that attended the school in the previous year and their siblings.

2. Free or reduced-price lunch eligible (i.e. low-income, FRPL) students applying to schools where less than half of the previous year's school population was FRPL.

3. Students applying to a school within their own "choice zone."14

Applicants were sorted by priority group according to these rules and then assigned a random lottery number. Slots at each school were first filled by students with guaranteed access, and then remaining slots were offered to students within each priority group in order of their lottery numbers. CMS administered all of the lotteries centrally and applied an algorithm known as a "first choice maximizer" (Abdulkadiroglu and Somnez 2003). Although this type of mechanism is not strategy-proof, Hastings, Kane, and Staiger (2008) find little evidence of strategic choice by parents.

I begin with the full sample of middle and high school applicants. Since nearly all rising 12 th graders received their first choice, I restrict the analysis sample to grades 6 through 11. Next I exclude the $5 \%$ of students who were not enrolled in any CMS school in the previous year. These students were much less likely to be enrolled in CMS in the following fall. Because previous enrollment was fixed at the time of the lottery, this

14. CMS divided schools into four "choice zones" and guaranteed transportation for students who applied to a school within their zone. This included magnet schools. The zones were constructed so that there was an even mix of mostly white "suburban" and mostly black "inner-city" schools in each zone. In practice, this priority group was rarely used since very few students applied outside their choice zone. 
restriction does not bias the results. The analysis sample consists of 21,132 high school students and 22,896 middle school students. The first column of Table I contains summary statistics for this sample. About $60 \%$ of the sample chose (and were automatically admitted to) their neighborhood school first. As shown in column (2) of Table I, the remaining $40 \%$ are more likely to be black and free lunch eligible, and they had lower test scores and higher rates of absence and out-of-school suspensions. About 75\% of applicants to nonguaranteed schools were in lottery priority groups where the probability of admission was either 0 or 1 . Even though these students chose a nonguaranteed school, there is no random variation in admission to exploit. In column (3) of Table I we see that the lottery subsample is similar to other applicants to nonguaranteed schools. The final lottery sample consists of 1,891 high school students and 2,320 middle school students.

Under busing schools were racially balanced, but the surrounding neighborhoods remained highly segregated. Thus the redrawing of school boundaries led to concentrations of minority students in some schools. Students who were assigned to these schools attempted to get out of them. Figure I displays the strong correlation between the racial composition of a school's neighborhood zone and the percent of students assigned to it who choose not to attend. Unlike many other studies of school choice, applicants to nonguaranteed schools are more disadvantaged than students who choose their neighborhood school. ${ }^{15}$ Even within high-minority schools, from which most of the sample is drawn, lottery applicants are similar in terms of race, socioeconomic status, and average test scores to students who chose to remain in their neighborhood schools. ${ }^{16}$ Still, since lottery applicants had different preferences than their peers who chose to stay in the neighborhood school, they may differ on unobserved dimensions.

15. See Online Appendix Table II for an analysis of selection into the lottery sample in a regression framework.

16. I test this by estimating a regression of the percent who listed the neighborhood school as their first choice on indicators for race and free lunch status, prior test scores, and home school fixed effects. In the full sample, students who chose their neighborhood school are about 10 percentage points more likely to be white and 8 percentage points less likely to be free lunch eligible, but have similar average test scores. When I restrict the sample to schools that are more than $60 \%$ nonwhite, the coefficients get smaller ( 5 and 3 percentage points) and marginally significant, and the results for test scores are unchanged. 


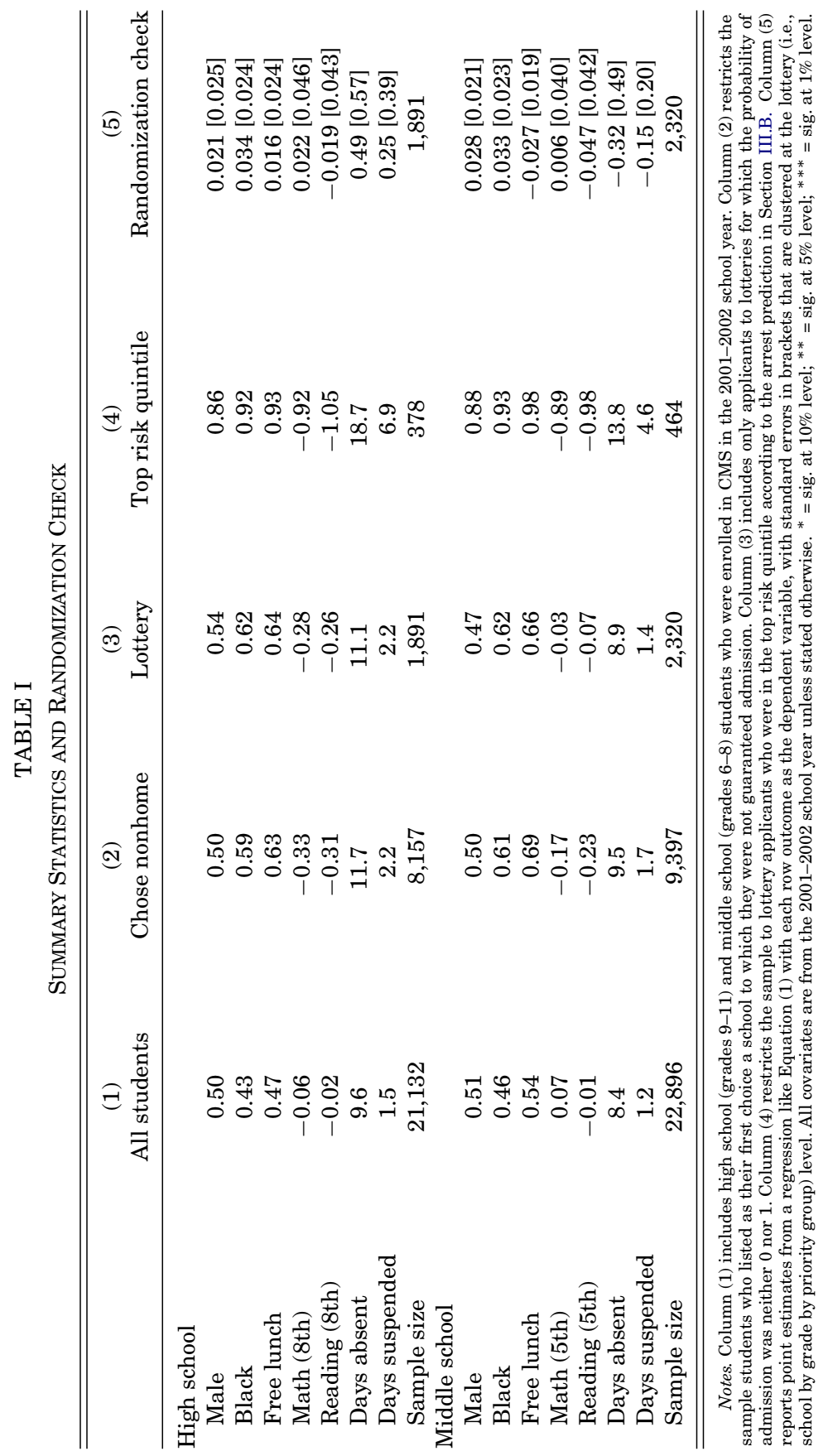




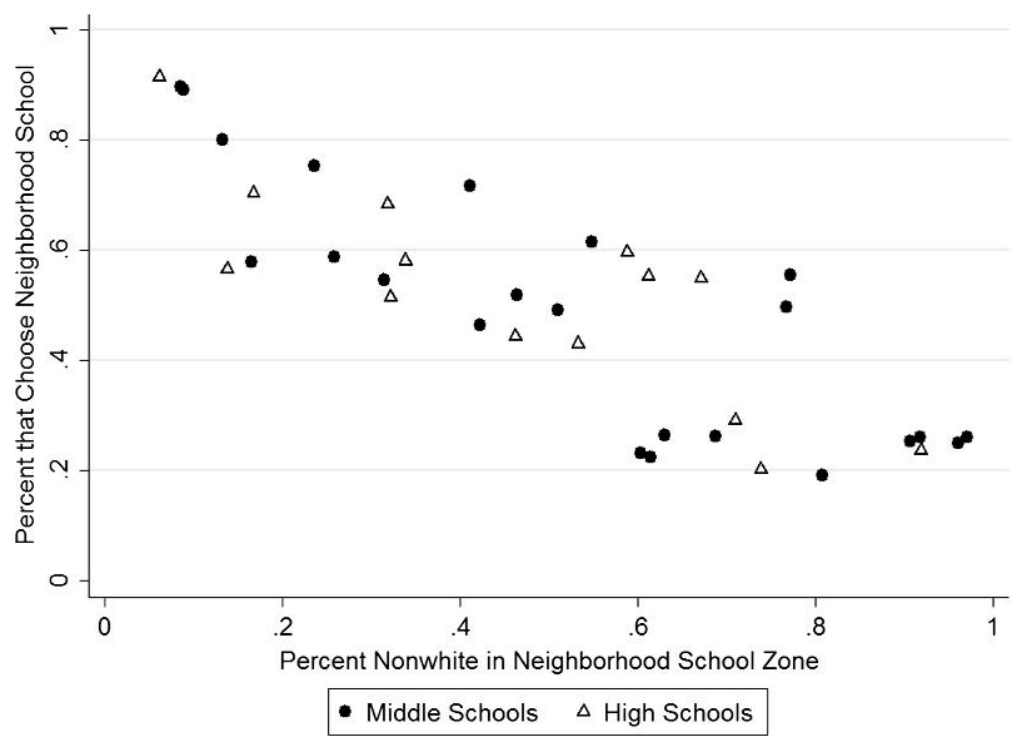

FiguRE I

Students in High Minority School Zones More Likely to Exercise Choice

CMS was divided into geographic catchment areas for the 2002-2003 school year and students were assigned to a neighborhood school zone based on their home address. The $y$-axis shows the share of students in the catchment area that chose their neighborhood school in spring 2002. The $x$-axis shows the percent of students in each catchment area that are nonwhite (based on their spring 2002 home addresses). Middle schools are students in rising grades 6-8 for fall 2002 . Since we exclude 12th-grade students in the main analysis, the high school means are based on students who will be in grades 9-11 in fall 2002 .

\section{EMPIRICAL STRATEGY AND IMPACT OF WINNING THE LOTTERY ON ENROLLMENT}

If lottery numbers are randomly assigned, the winners and losers of each lottery will on average have identical observed and unobserved characteristics. Thus with sufficient sample size, a simple comparison of mean outcomes between winners and losers would identify the causal effect of winning each individual lottery. However, the sample here is not large enough to estimate the effect of winning each individual lottery. Instead, following Cullen, Jacob, and Levitt (2006), I estimate ordinary least squares regressions of the form:

$$
Y_{i j}=\delta W_{i j}+\beta X_{i j}+\Gamma_{j}+\varepsilon_{\mathrm{ij}}
$$


$Y_{i j}$ is an outcome variable of interest for student $i$ in lottery $j \cdot W_{i j}$ is an indicator variable equal to 1 if student $i$ in lottery $j$ had a winning randomly assigned lottery number, and 0 if not. $X_{i j}$ is a vector of covariates included for balance, $\Gamma_{\mathrm{j}}$ is a set of lottery (i.e., choice by grade by priority group) fixed effects, and $\epsilon_{i j}$ is a stochastic error term. I consider only first choices, so the number of observations is equal to the number of students in the lottery sample. In principle I could estimate a nested model that incorporates multiple choices. However, in practice nearly every student who did not receive their first choice was either automatically admitted to their second choice (if it was not oversubscribed) or automatically denied because all the slots were already filled.

Lottery fixed effects are necessary to ensure that the probability of admission to a first-choice school is uncorrelated with omitted variables in the error term. If, for example, savvy parents had some prior knowledge about the chance of admission, they might (all else equal) apply to schools where the probability of acceptance was higher. Thus comparing winners and losers across different lotteries might lead to a biased estimate. In the specification in Equation (1), the $\delta$ coefficient gives the weighted average difference in outcomes between winners and losers across all lotteries, with weights equal to the number of students in the lottery times $p *(1-p)$ where $p$ is the probability of admission (Cullen, Jacob, and Levitt 2006). Thus $\delta$ represents the intention-to-treat (ITT) effect of winning admission to a first-choice school for students in priority groups with nondegenerate lotteries. I cannot estimate the effect of attending a school for students with guaranteed access.

If the lotteries were conducted correctly, there should be no difference between winners and losers on any characteristic that is fixed at the time of application. I test this directly by estimating Equation (1) with pretreatment covariates such as race, gender, and prior test scores as outcomes. The results, in the last column of Table I, show that the lottery was balanced on observables and the randomization seems to have been conducted correctly. Even with proper randomization, however, the estimates could still be biased by selective attrition if leaving CMS or Mecklenburg County is correlated with winning the lottery. Since high school dropout rates are high for crime-prone youth, selective attrition is a serious concern for outcomes that come from the CMS administrative 
data. Students who drop out of school and are subsequently arrested in Mecklenburg County, however, are included in the data. Thus the main issue is selective migration. If lottery losers are more likely to leave the county, they may commit crimes in other jurisdictions. This would bias estimates downward. On the other hand, lottery winners may perform better in school and be more likely to leave the county to go to college, for example. This would bias the estimates upward. Even so, there are a few reasons to think that selective migration is not much of a concern here. First, the population of crime-prone youth is not very mobile. Attrition in grades $\mathrm{K}$ through 8 (where dropout is less of an issue) is negatively correlated with other predictors of crime and is much lower than average among future criminals. ${ }^{17}$ Second, CMS assigns a withdrawal code to students who leave the district, and lottery status is uncorrelated with the code for out-of-county transfers. Additionally, the NCDOC state prison data includes information on county of arrest. Less than $1 \%$ of the sample spent time in state prison for offenses committed outside of Mecklenburg County, and there is no difference between lottery winners and losers.

\section{III.A. Predictors of Crime and Heterogeneous Treatment Effects}

Most members of the lottery sample are probably not at high risk for criminal offending. Likewise, a small percentage of high-rate offenders are responsible for a large share of crimes (Wolfgang, Figlio, and Sellin 1987; Freeman 1994). To test for heterogeneous treatment effects, I exploit the unusually long and rich panel of administrative data from CMS. Students with adult arrest records can be tracked all the way back to kindergarten in some cases, with yearly information on test scores and behavior and detailed neighborhood measures. I combine all of the individual correlates of criminal behavior into a single index and plot the treatment as a function of this ex ante crime risk. I estimate the probability that a student will have at least one arrest as a function of their history of test scores and behavior measures, demographic characteristics, and neighborhood of residence. These measures are strong predictors of

17. Ninety-one percent of future felons who were enrolled in CMS in fourth grade were still enrolled 4 years later (what would have been their eighth-grade year). The overall average is $80 \%$. 
future criminality. ${ }^{18}$ See Online Appendix Table III for more details on the estimation and for regression coefficients from this prediction.

In column (4) of Table I, I present the average characteristics of youth who are in the top risk quintile according to this prediction. About $90 \%$ of the high risk sample is comprised of free lunch-eligible African American males. Their test scores are on average one standard deviation below the North Carolina state average, and they are absent and suspended many more days than the average student. Because the high-risk students are overwhelmingly male, I exclude females from all subsequent analyses. ${ }^{19}$

To test for the possibility of heterogeneous treatment effects, I rank male youth according to their arrest risk and split the sample into five quintiles. I then estimate:

$$
Y_{i j}=\sum_{q=1}^{5} \delta_{q} W_{i j}+\sum_{q=1}^{5} \phi_{q}\left(1-W_{i j}\right)+\beta X_{i j}+\Gamma_{j}+\varepsilon_{\mathrm{ij}},
$$

where $q$ indexes risk quintiles, and the rest of the notation is similar to Equation (1). Separate coefficients by risk quintile for lottery winners $\delta_{q}$ and lottery losers $\phi_{q}$ allow me to test the hypotheses that lottery winners and losers are equal overall and within each quintile and that the arrest risk quintiles are statistically different overall or within each group. I first estimate Equation (2) for the main crime outcomes and plot the treatment effects and associated confidence intervals against each risk quintile. I then estimate simpler models where the first through fourth quintiles are pooled but the lottery is allowed to have a different effect on the top quintile "high-risk" youth.

18. The pseudo $R$-squared from the regression is about 0.23 , compared with 0.24 when high school graduation is the dependent variable. Joint tests for the significance of each type of coefficient yield chi-squared values of 147 for test scores, 471 for behavior, and 249 for neighborhood fixed effects.

19. I show in the Online Appendix Table IV that the number of arrests among females is extremely low, particularly for serious crimes. The crime prediction model greatly understates actual gender gaps in criminal offending. One way to show this is to regress a crime outcome such as felony arrests on the arrest prediction plus indicators for gender, race, and free lunch status. The male coefficient comes in highly significant, while race and free lunch are insignificant, suggesting that the model does not do a good job accounting for gender differences. Results with females included are qualitatively similar, but do not identify "highrisk" youth as accurately. 
III.B. Impact of Winning the Lottery on Measures of Enrollment and School Quality

Table II presents enrollment impacts in the years following the lottery. Columns (1) through (4) present results for high school lottery applicants; columns (5) through (8) show the same for middle school applicants. The coefficients come from a regression like Equation (2), but with the lowest four risk quintiles pooled together and a separate estimate for the top risk quintile. The odd-numbered columns present control means for the estimates in each row. Below each estimate and in subsequent tables, I report standard errors that are clustered at the individual lottery (i.e., choice by grade by priority group) level. The first row shows the effect of winning the lottery on attendance at a student's first choice school in spring of the 2002-2003 school term, a year after the lottery was conducted. The first stage is strong-lottery winners in all groups are over 55 percentage points more likely than losers to attend their first-choice school. The coefficient is less than 1 mainly because some lottery losers successfully enroll in their first choice anyway. ${ }^{20}$ For the main results herein, I report ITT estimates of the effect of winning the lottery. Later I discuss results that use the lottery as an instrumental variable for several of the outcomes in Tables II and III. Because a nontrivial fraction of lottery losers still manage to enroll, these estimates are not generalizable to all lottery applicants. Instead, they are local average treatment effects (LATEs) for students who comply with their lottery status (Angrist, Imbens, and Rubin 1996).

The second row shows the effect of winning the lottery on total years enrolled in the first-choice school. The third row expresses the change in enrollment as a proportion of the total that was possible for a student that was progressing on time, and the fourth row shows the percentage of students who were enrolled for the maximum number of years. This number ranges from 1 (for 8 th and 12th grade students) to 4 (for 9th grade students.) The treatment consisted of 1 to 1.5 additional years of enrollment on average, or about a 35 to 50 percentage point increase as a share of total possible enrollment. The effect sizes are a bit smaller

20. Some students moved into the school's neighborhood zone in summer 2002, after losing the lottery. Some lotteries were for special programs within schools, so a student might have been denied admission to the special program but accepted to the regular school. Finally, some students may have been admitted at the beginning of the school year when lottery winners did not enroll. 


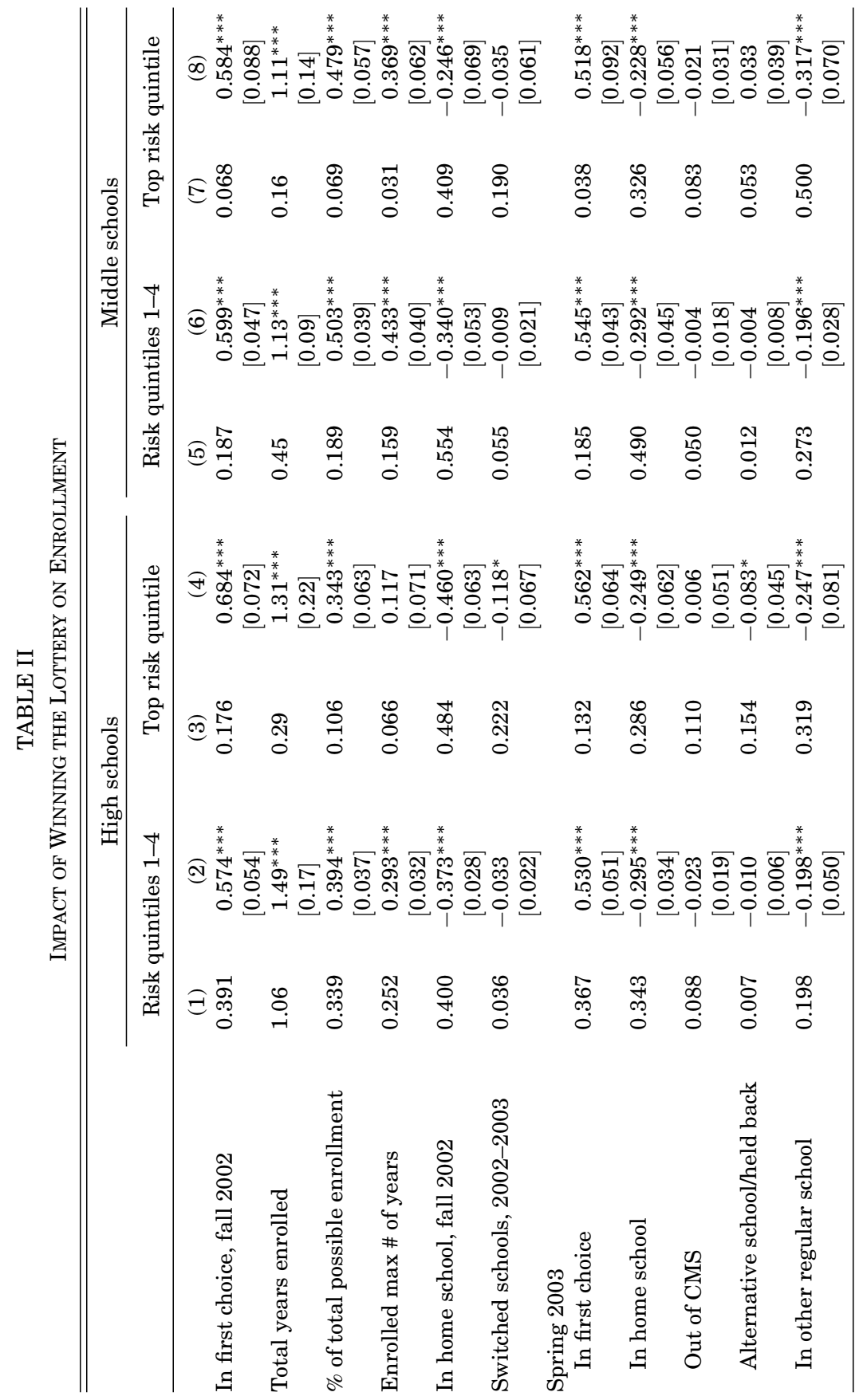




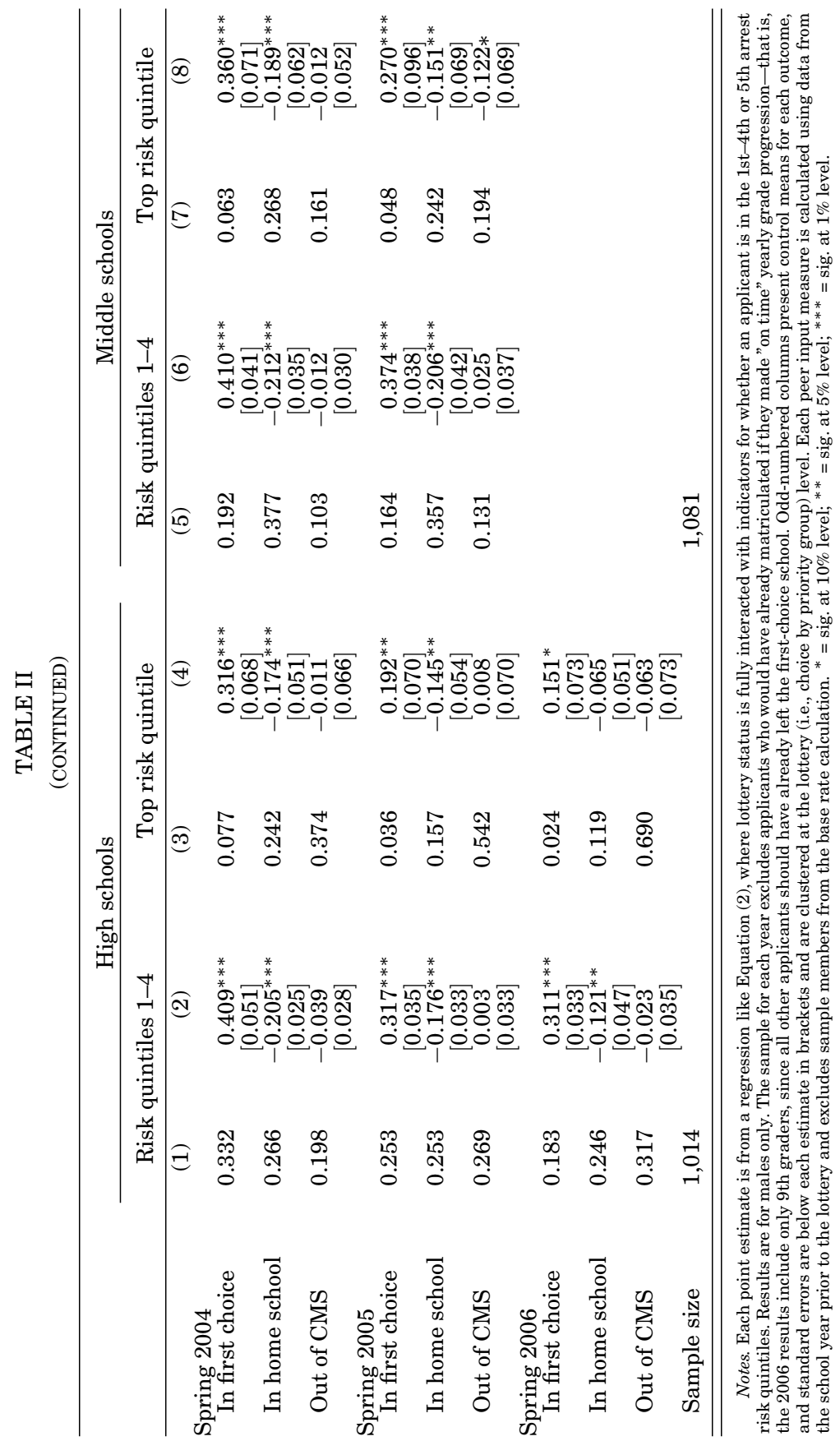


for high-risk youth, but relative to a much lower baseline. This suggests that the treatment "dose" was proportionally larger for high-risk youth. The fifth row shows the effect of winning the lottery on attendance at the student's neighborhood school, which is highly negative for all groups. About $40 \%$ to $55 \%$ of lottery losers enrolled in their neighborhood school in fall 2002, compared with fewer than $5 \%$ of high school lottery winners and $15 \%$ to $20 \%$ of middle school lottery winners. The sixth row shows the impact of winning the lottery on the probability of switching schools during the 2002-2003 school year. High-risk lottery winners in high school are 12 percentage points less likely to switch schools, but there is no statistically significant impact on high-risk middle school applicants.

The rest of Table II presents impacts on enrollment by type of school from 2003 to 2006 . The results for spring 2003 consist of five mutually exclusive options-the student is either in their first-choice school, in their neighborhood (or "home") school, not in any CMS school, in an alternative school for youth with behavioral problems, or held back to elementary/middle school, in another regular school. A few results are notable. Less than $10 \%$ of lottery winners in the top risk quintile return to their neighborhood schools, compared with $25 \%$ to $30 \%$ for lottery losers. Although there is no impact on dropout, high school lottery winners in the top risk quintile are over 50\% less likely to be in an alternative school in spring 2003. In subsequent years I restrict to the first three options, with other schools as the left-out category. In each year I exclude lottery applicants for whom "on-time" progression would result in matriculation from the school (i.e., rising eighth grade applicants are only in the spring 2003 middle school sample, since they would move on to high school in 2004). ${ }^{21}$

The effect of winning the lottery on enrollment in a firstchoice school remains statistically significant in all years. Yearly attrition from the first-choice school (observed by comparing the first-choice enrollment results by year), however, is higher for high-risk youth and for the high school sample overall, primarily

21. Sample sizes decrease by year as a result of this restriction. The 2006 results are only for the 645 rising 9th grade male applicants (who would have been in 12th grade by 2006). For high school applicants, the other sample sizes are 905 (9th and 10th grade) for the 2005 outcomes and 1,014 (9th, 10th and 11th grade) for the 2003 and 2004 outcomes. For middle school applicants, the sample sizes are 561 for the 2005 outcomes (6th grade only), 824 for the 2004 outcomes (6th and 7th grade), and 1,081 (6th, 7th and 8th grade) for the 2003 outcomes. 
because of dropout. Dropout rates are extremely high among high school youth in the top risk quintile. The share of lottery winners in their neighborhood schools remains low in subsequent years. For middle school lottery winners, nearly all of the attrition in first-choice enrollment is accounted for by other regular CMS middle schools. Notably, rising sixth-grade lottery winners in the top risk quintile are $63 \%$ (12 percentage points) less likely to have left CMS by spring 2005, their eighth-grade year.

Table III shows the effect of winning the lottery on school characteristics. The first three rows show the racial and family income composition of the school and on distance to assigned school. High school lottery winners attend schools that are demographically very similar to the schools attended by lottery losers, whereas middle school winners attend schools that are less African American and higher income on average. All lottery winners travel farther to attend their first-choice school, but the distance is greater for high school students.

The next seven rows of Table III show the effect of winning the lottery on various measures of school quality. I first test the impact of winning the lottery on peers' average math scores in the year prior to the lottery. ${ }^{22}$ High school lottery winners in the top risk quintile and all middle school lottery winners experience modest increases in peer test scores of about 0.15 standard deviations. The next row shows the impact of winning the lottery on peers' average predicted criminality. I use the results from the estimation procedure outlined in Section III.A., where peer groups are a student's school and grade, and I exclude members of the lottery sample from calculation of the average. ${ }^{23}$ Lottery winners in the top risk quintile experience modest decreases in the predicted criminality of peers. The results are about $75 \%$ larger and estimated more precisely for the middle school sample. We can interpret this coefficient as the change in the predicted percentage of a student's cohort that will have an arrest recordfor example, middle school lottery winners in the top risk quintile

22. Since state-standardized exams are administered in math and reading up to grade 8, I use the prior (2001-2002) year's exam for rising grades 6 to 9 , but data from earlier years for grade 10 and 11 . The lottery sample is excluded from calculation of the average. Results for the reading test score are very similar.

23. I use grade-specific peer criminality because of the change in school assignments in the 2002-2003 year. A student's class composition can often differ substantially from the other cohorts in the school. The results from an overall school mean, however, are very similar. 


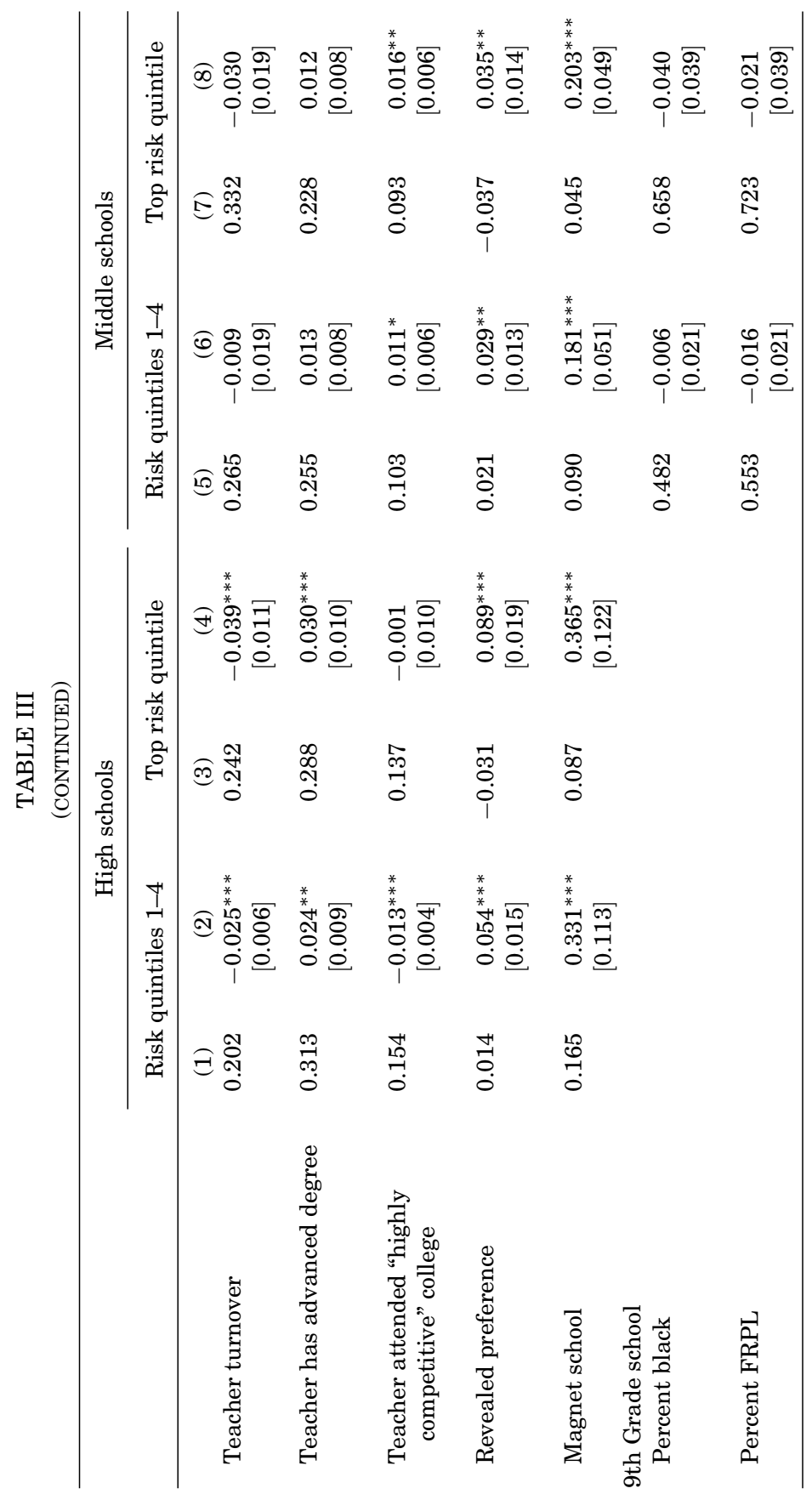




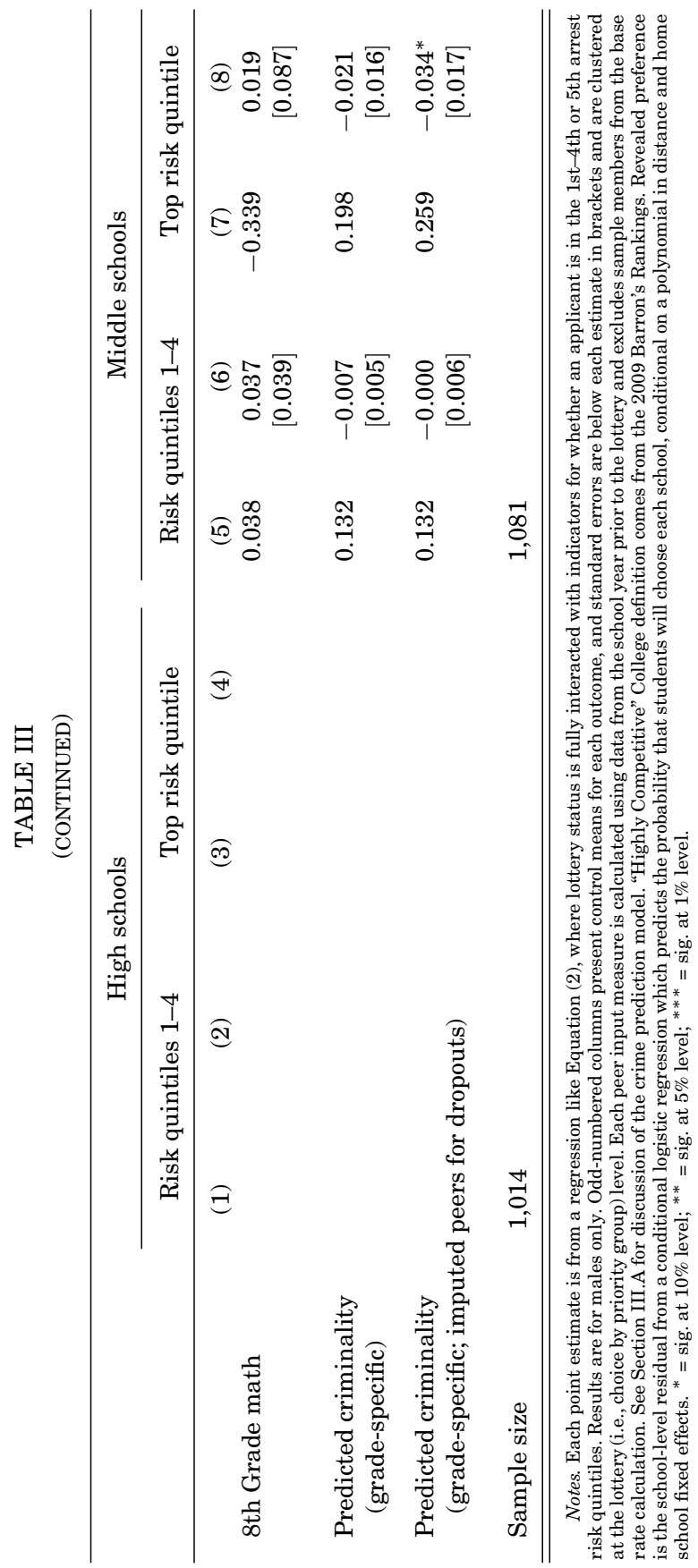


attend schools where $15.8 \%$ of students are predicted to have an arrest record, compared with $17.9 \%$ for lottery losers.

The next four rows present results for four measures of teacher quality - the fraction of novice (defined by the NCDPI as less than 3 years of experience) teachers, the fraction of teachers that are new to the school that year, the percent of teachers with an advanced degree, and the share of teachers that attended a "highly competitive" college as defined by the Barron's rankings. ${ }^{24}$ Lottery winners in the top risk quintile show improvements on all four measures of teacher quality, although the results are larger and more often statistically significant in the high school sample. The revealed preference measure is the school residual from a conditional logistic regression that predicts the probability that students will list each school as their first choice, conditional on a third-order polynomial in distance and home school fixed effects. Lottery winners attend schools that are more preferred overall, and the impacts are larger for the high school sample. This is perhaps unsurprising because only oversubscribed schools are in the lottery sample, but the relative magnitudes are informative. The final quality measure is an indicator for whether a student attends a magnet school. Magnet school enrollment comprises a larger share of the treatment in the high school sample, mostly due to the opening of a new magnet high school (Philip Berry Academy of Technology, a "career academy" that focuses on vocational and technical education) in the 2002-2003 school year. This is notable since a recent randomized evaluation of the Career Academies program found that male participants had substantially higher earnings after 9 years of follow-up, despite no impact on test scores or high school graduation (Kemple and Willner 2008). Overall, lottery winners attend schools that are better on every dimension. Across multiple measures, the gain in school quality for highrisk youth is larger than for the overall sample and starts from a much lower baseline, as indicated by the control means in each odd-numbered column. For youth in the top risk quintile, the gain in measured quality is roughly equivalent to moving

24. The first three measures are taken from school averages that are reported on the NCDPI website, while the last measure comes from CMS administrative data. Data on college attended is missing for about $35 \%$ of teachers overall, and the share is higher for the schools attended by "high-risk" students. For all of these measures, the lack of student-teacher matched data means I am unable to tell how much of the increased teacher quality is actually experienced by lottery winners. Jackson (2009) shows that teachers in CMS switch schools in response to the end of busing. 
from one of the lowest-ranked schools to one around the district average.

The last five rows of Table III show the effect of winning the middle school lottery on high school characteristics. The sample is by necessity limited to students who were still enrolled in CMS in ninth grade. Although middle school lottery winners appear to attend better schools initially, these gains do not extend beyond the initial treatment. There is no statistically significant impact of winning the middle school lottery on the demographic composition, average test scores, or predicted criminality. However, as we saw in Table II, winning the lottery has an impact on whether students remain in CMS through the end of eighth grade. In the last row of Table III, I reestimate the impact on peer criminality except I include the missing students and assign them peers with predicted criminality that is equal to the mean of their own risk quintile. Effectively, I am assuming that when they drop out, they associate with other students like them. With this admittedly imperfect measure of peer groups, we see that middle school lottery winners in the top risk quintile have peers that are statistically significantly less crime prone.

\section{RESULTS}

\section{IV.A. Crime}

Not all crimes are equal. Serious violent crimes such as murder, rape, and armed robbery exact a heavy burden on their victims, so any welfare calculation should weigh these crimes more heavily. I measure crime severity in two ways. First, I use estimates of the victimization cost of crimes produced by Miller, Cohen, and Wiersema (1996). These estimates, which were also used in an analysis of the of the MTO Demonstration by Kling, Ludwig, and Katz (2005), consider tangible costs such as lost productivity and medical care, as well as intangible costs such as impact on quality of life, and are extremely high for fatal crimes. ${ }^{25}$ To avoid the estimates being driven entirely by a few

25. The estimated social cost of murder is $\$ 4.3$ million in 2009 dollars. The next costliest crime is rape, at about $\$ 125,000$. Miller, Cohen, and Wiersema (1996) do not include social cost estimates for drug crimes. Following Kling, Ludwig, and Katz (2005), I assign costs to drug crimes according to felonies of equivalent standing. If instead I set the cost of drug crimes to zero, the estimates fall by about $25 \%$ in the high school sample but are unaffected for middle schools. 
murders, I also report results with the cost of murder trimmed to twice the cost of rape, following Kling, Ludwig, and Katz (2005). The second measure of severity weighs crimes by the expected punishment resulting from a successful conviction. In 1994 the state of North Carolina enacted the Structured Sentencing Act. Under structured sentencing, felony convictions are grouped into classes based on severity. This information is combined with the offender's prior record and other circumstances to determine a range of possible sentence lengths available to the judge. I group felony charges according to their class and assign the midpoint of the range of sentences for each of them. While both measures place a very high weight on murder, for example, the sentence weighted measure is better able to capture criminal intent. ${ }^{26}$ I also examine the effect of winning the lottery on total days incarcerated in the county jail and state prison systems. These data are only available for African American male members of the sample, from 2006 to the present. Since most high school sample members were already age 20 or older by 2006, I am missing prison time served during the peak criminal offending ages of 18 to 19 . Incarceration data is likely to be much more complete for the middle school sample, however.

The main results of this article are in Figures II and III and in Table IV. I first estimate Equation (2) for selected crime outcomes and plot the point estimates and 90\% confidence intervals by arrest risk quintile in Figures II and III, for the middle and high school samples, respectively. Each graph plots the coefficients from a model like Equation (2), with a full set of lottery status by risk quintile interactions. The $p$-values from $F$ tests for equality of effects overall (and for each quintile, when statistically significant) and equality of quintiles (in levels) are displayed on each graph. In Figure II, we see that winning the lottery leads to fewer felony arrests overall $(p=.078)$, and the effect is concentrated among the highest risk youth ( 0.77 felony arrests for lottery losers, 0.43 for winners, $p=.013$ ). Similarly, the trimmed social cost of crime is lower overall for lottery winners $(p=.040)$, but the effect is concentrated among the top risk quintile youth ( $\$ 11,000$ for losers, $\$ 6,389$ for winners,

26. The difference between manslaughter and aggravated assault often comes down to luck (i.e., whether the bullet hit a critical organ or just missed it). The social cost measure would treat these two outcomes very differently, whereas the expected sentence length for these two crimes is very similar. 


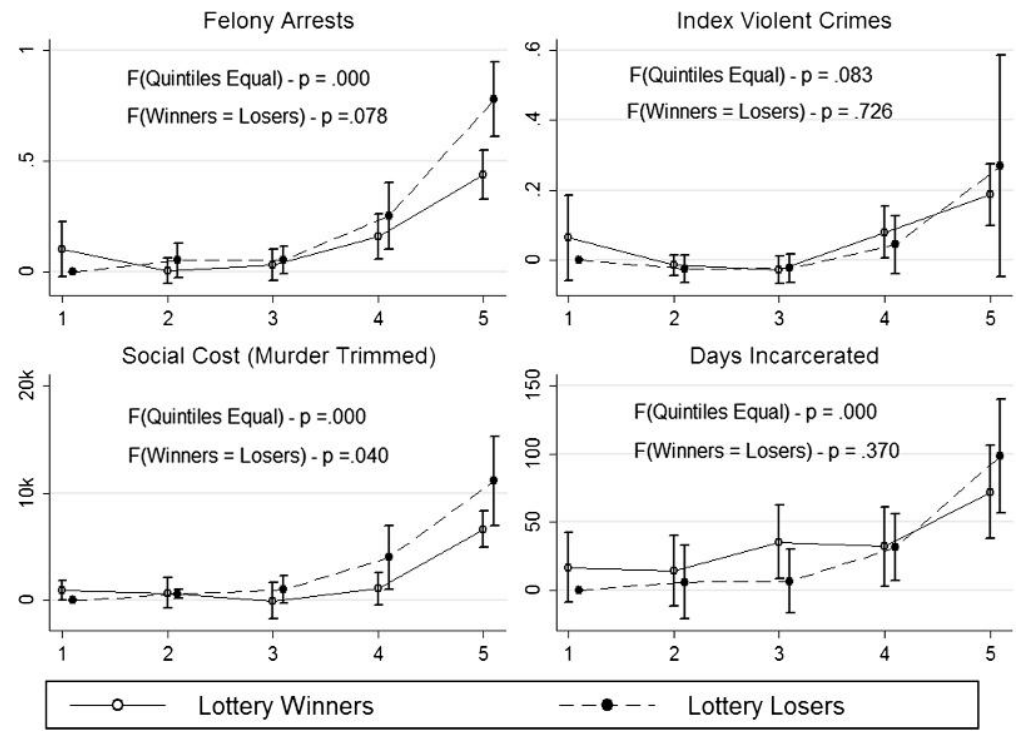

FIGURE II

Impact of Winning the Lottery on Crime, by Arrest Risk Quintile

High School Sample

Each point estimate and $90 \%$ confidence interval are taken from a regression like Equation (2) where the lottery treatment is fully interacted with indicators for whether a youth is in each risk quintile. $F$-tests for equality of treatment and control groups across all five quintiles and for equality of quintiles in levels are presented on each graph. The sample size is 1,014, except for the Days in Prison outcome, which is available for African Americans only $(N=610)$.

$p=.036$ ). The concentration of effects in the top risk quintile is even more pronounced for the middle school sample. The social cost of arrested crimes is $\$ 12,500$ for middle school lottery losers and $\$ 4,643$ for winners $(p=.020)$, and the effect for days incarcerated is similarly large and concentrated among high-risk youth (55.5 days for losers, 17.2 for winners, $p=.003$ ). For each of the eight outcomes in Figures II and III, the level of crime committed by the top risk quintile is over twice that of the fourth quintile, and we can reject equality of quintiles at the $10 \%$ level for all eight outcomes. $^{27}$

27. Although I do not report the test statistics, equality of the fourth and fifth risk quintiles among lottery losers is rejected for all eight outcomes in Figures II and III. 

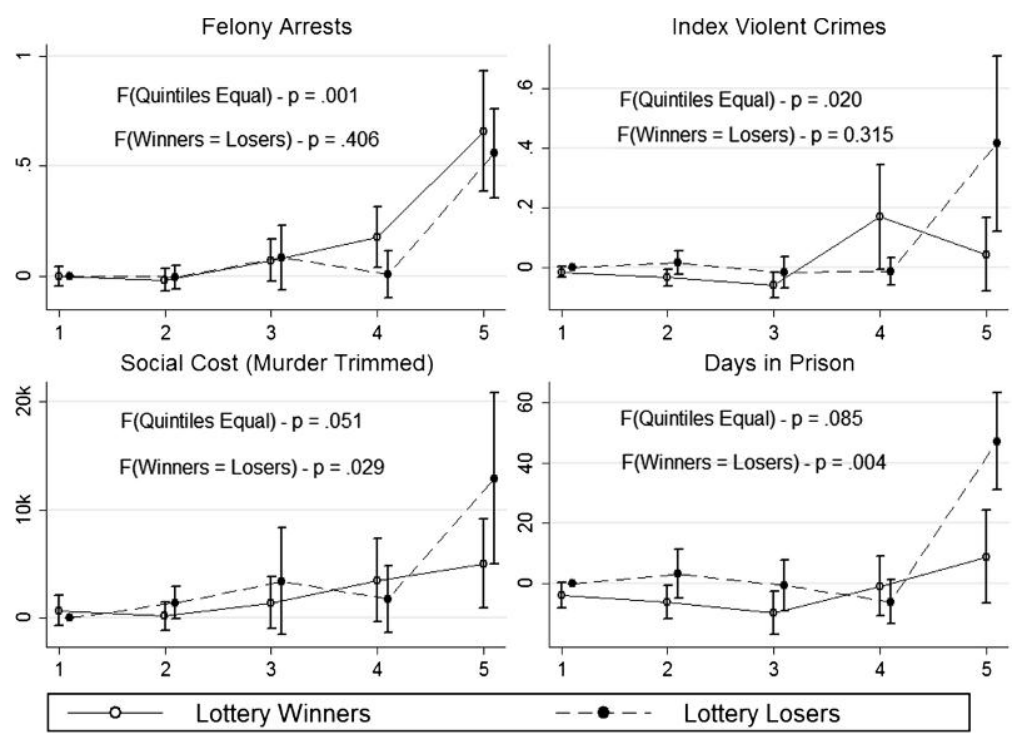

FIGURE III

Impact of Winning the Lottery on Crime, by Arrest Risk Quintile

Middle School Sample

Each point estimate and $90 \%$ confidence interval are taken from a regression like Equation (2) where the lottery treatment is fully interacted with indicators for whether a youth is in each risk quintile. $F$-tests for equality of treatment and control groups across all five quintiles and for equality of quintiles in levels are presented on each graph. The sample size is 1,081, except for the Days in Prison outcome, which is available for African Americans only $(N=649)$.

Table IV shows regression results from a modified version of Equation (2) where the first four risk quintiles are pooled, but the effect is allowed to vary for the top risk quintile. ${ }^{28}$ In the first four columns I report estimates with the high and middle school samples pooled, with separate coefficients (from the same regression) for quintiles 1-4 and quintile 5. The first five rows show results for arrests overall and by type of crime. The last four rows show results for four measures of crime that are weighted by severity-social cost without and with the cost of murder trimmed, crimes weighted by expected sentence, and days incarcerated. The odd-numbered columns contain control means for each outcome, and the even-numbered columns show coefficients

28. The models in columns (5)-(8) are estimated with the first through fourth risk quintile youth included, but I do not include the coefficients in the table. 
and standard errors. The first thing to note is the concentration of crime within the top risk quintile. High-risk youth are arrested about six times more often than the rest of the sample and spend about nine times as many days incarcerated. These differences are even larger for index violent crimes and drug felonies. This and the graphical evidence in Figures II and III suggest that the crime prediction model focuses the analysis on the right set of youth. Top risk quintile lottery winners have fewer non-traffic and felony arrests overall, although the results are not statistically significant in the pooled sample.

Each of the outcomes in the last four rows of Table IV weighs crimes by severity. Winning the lottery led to an estimated reduction in the social cost of arrested crimes of over $\$ 30,000$ for the top risk quintile, and over $\$ 12,000$ for risk quintiles $1-4$. Since more murders were committed by the control group than the treatment group (five versus one in the combined high and middle school samples), the estimates are large and negative but relatively imprecise. When the cost of murder is trimmed, the effect becomes smaller but more precise. Winning the lottery led to a negative but insignificant drop of about $\$ 500$ per male applicant in the first through fourth risk quintiles, but a decrease of over $\$ 6,000$ per male applicant in the highest risk quintile. The effect for high-risk males is large (over $50 \%$ of the control mean) and statistically significant at the $1 \%$ level. The results are of similar size and significance for the sentence-weighted measure of crime severity. High-risk lottery winners commit crimes with a total expected sentence of about 26 months, relative to about 52 months for lottery losers. Finally, high-risk lottery winners spend about 40 days in prison, compared with 70 days for lottery losers. Both the sentence weighted and days incarcerated measures are statistically significant at the 5\% level. The high overall level of incarceration among high-risk youth is consistent with national trends-in 2006-2007, about 23\% of black male high school dropouts in the United States were incarcerated on any given day (Sum et al. 2009). Overall, high-risk lottery winners experienced about a 50\% reduction in the three measures that index crimes by severity.

Columns (5)-(6) and (7)-(8) show the top quintile results only for the high and middle school samples, respectively. Although the results for the main outcomes are similar, the pattern of effects by felony arrests is different in each sample. The high school sample is arrested less often overall, and the impact is driven entirely 


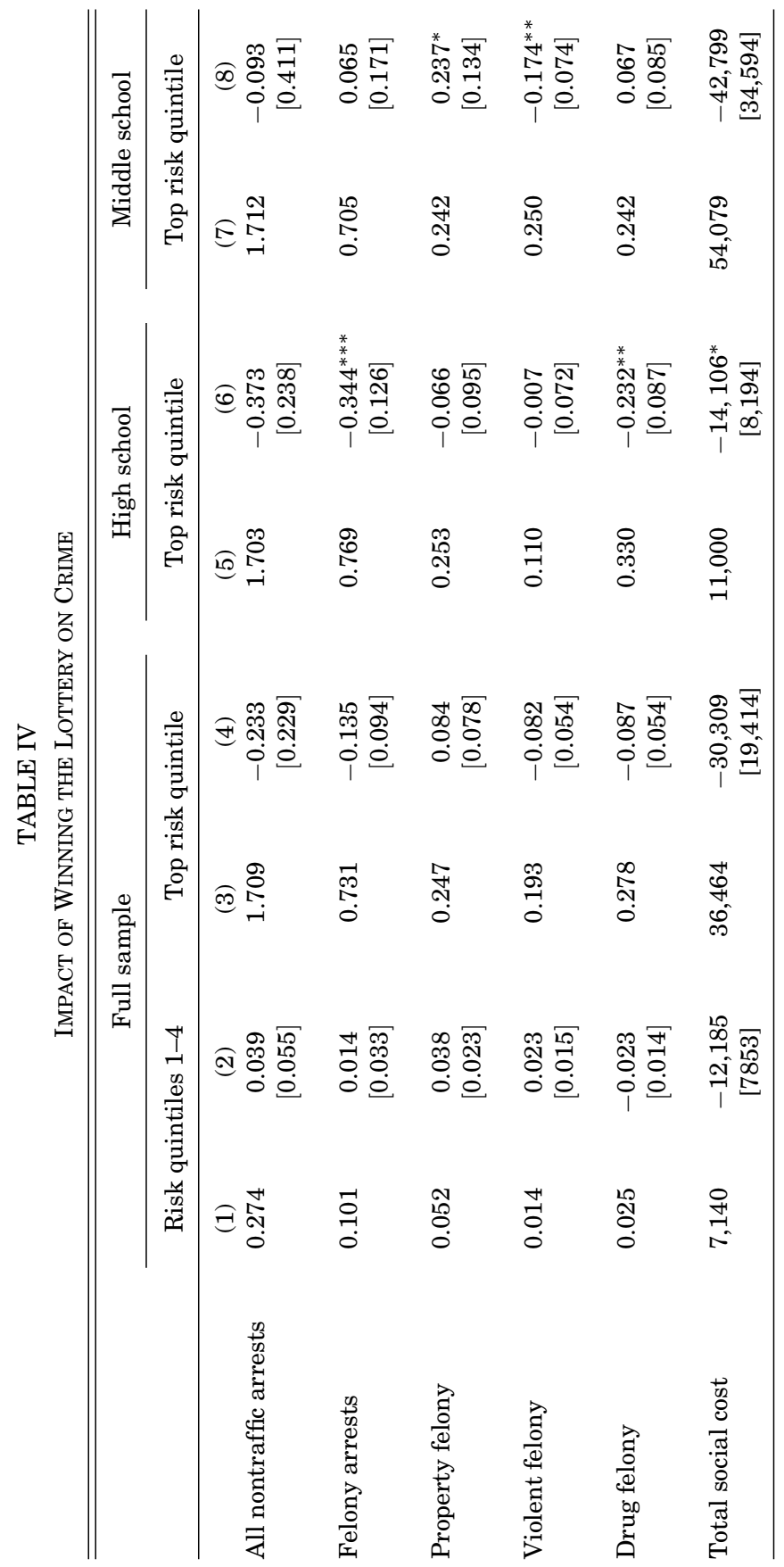




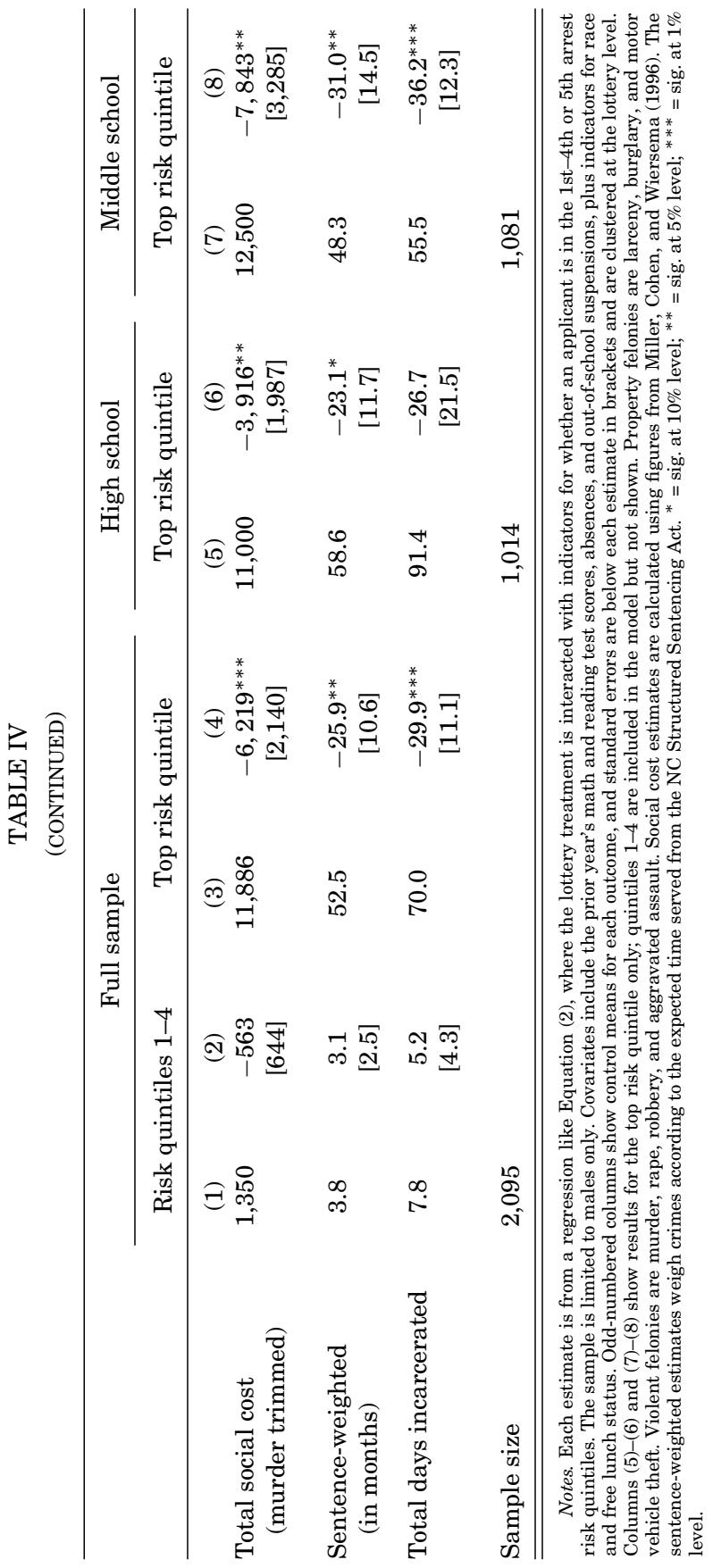


by a $45 \%$ reduction in felony arrests, and within that a $70 \%$ reduction in drug felony arrests. In contrast, there is no overall reduction in arrests in the middle school sample. Instead, high school lottery winners have about twice as many property arrests, but about $70 \%$ fewer violent felony arrests. Since these crimes have the highest social cost and are punished most severely, highrisk middle school lottery winners show statistically significant reductions in social cost, sentence weighted crimes, and days incarcerated of about $60 \%$ to $65 \%$. In Online Appendix Table IV I present results separated by race and gender. I find statistically significant reductions in crime for African American males overall, but nearly all of the results are statistically insignificant for other subgroups.

Winning the middle school lottery leads to substitution along the intensive margin of crime severity, and winning the high school lottery leads to fewer (primarily drug) arrests overall. Even though the effects are driven by high-risk youth in both middle and high schools, the middle school sample appears more crimeprone overall. The average number of arrests is similar in the top risk quintile for both samples, yet high school students have had many more years to accumulate arrests (and the average social cost of crimes is actually higher for the middle school sample). This is consistent with a developmental view of criminality, where delaying the onset of criminal offending among adolescents alters their future trajectory and prevents very serious crimes in the peak offending years (Moffitt 1993; Nagin and Tremblay 1999).

\section{IV.B. Pattern of Results over Time}

Tables V and VI present impacts on crime by years since random assignment, for top-risk quintile high school and middle school youth, respectively. Standard errors are in brackets below the estimates, followed by control means for each period in curly brackets. Although I estimate models with the full sample, I only report the point estimates for high-risk youth. The arrest measures in the first five rows are indicator variables that are equal to 1 if the youth was arrested at least once in each year. ${ }^{29} \mathrm{We}$ can see that the overall reduction in felony arrests is driven by years four and five, when youth are around age 18-19 and no longer

29. Alternative measures such as number of arrests or number of charges yield substantively similar results and are available on request. 


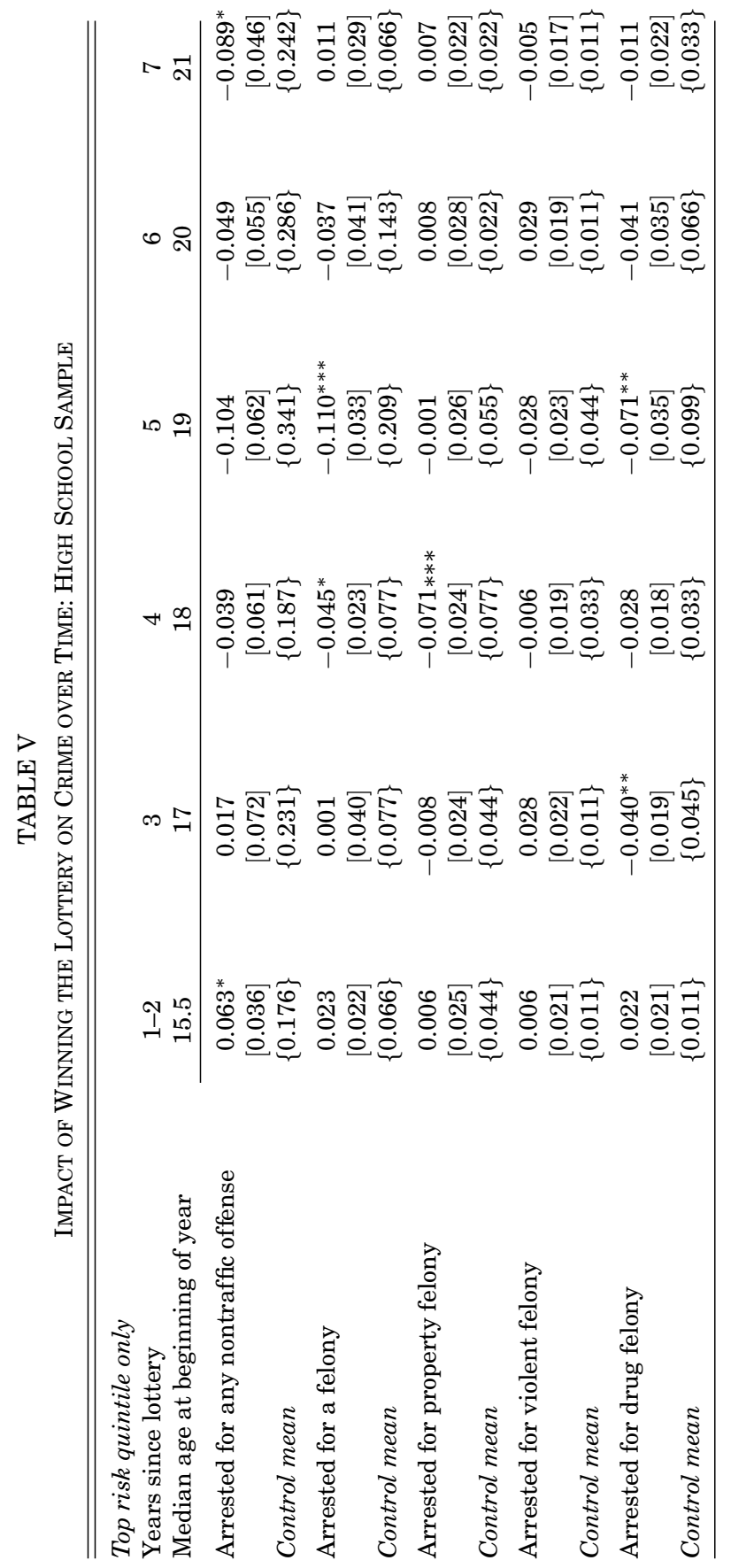




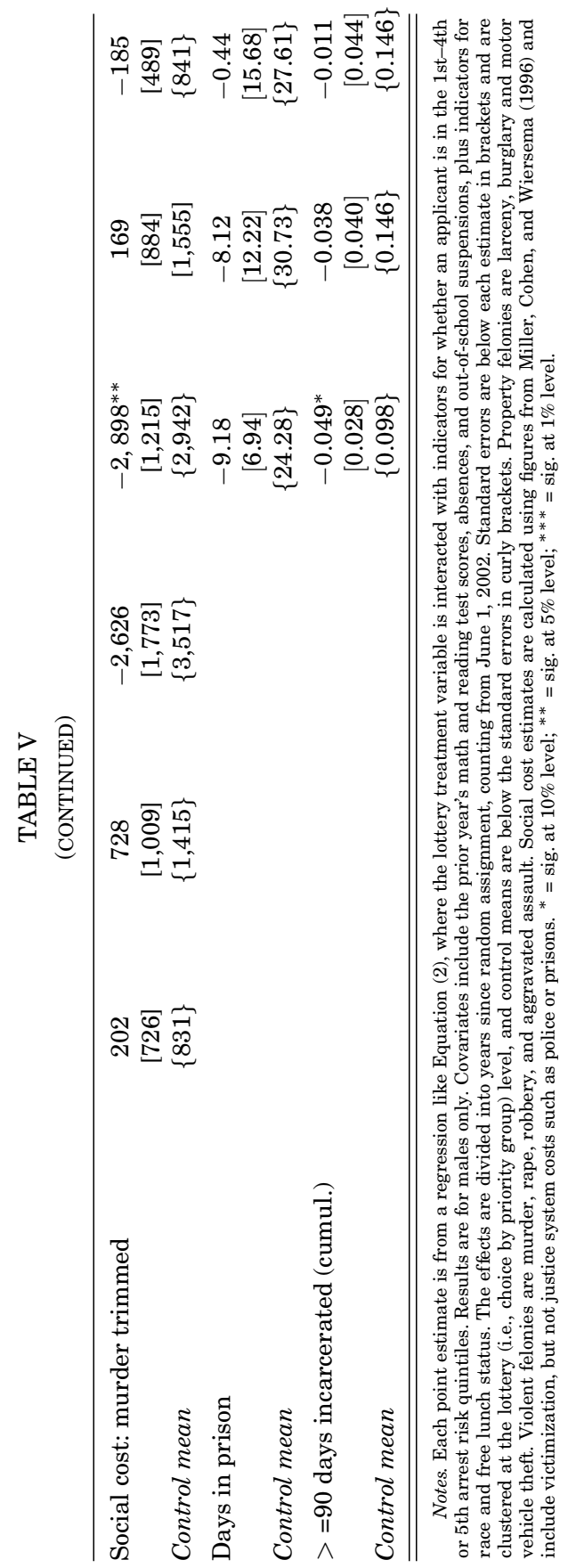




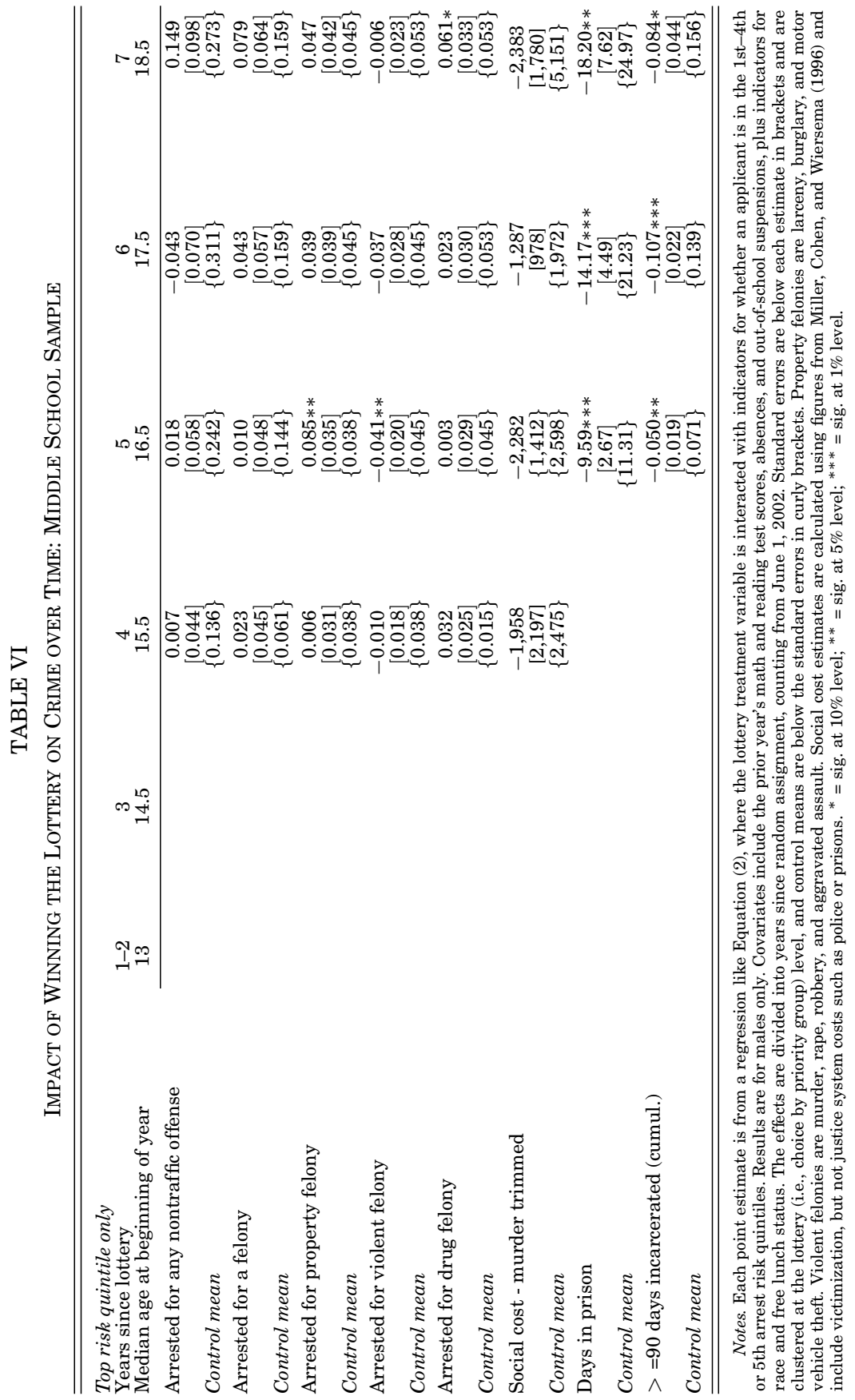


enrolled in their first-choice school. This also holds for the social cost measure. The last row of Table $V$ shows a cumulative measure of incarceration-whether a lottery applicant has spent 90 total days incarcerated in any year. High school lottery winners are about half as likely to have been incarcerated 90 or more days in year five, but this gap closes to only one percentage point by year seven.

Table VI presents the same set of results for high-risk youth in the middle school sample. We can see that most of the overall increase in arrests comes in the last 2 years, and that it is driven by nonviolent felonies. The decrease in violent felonies comes earlier, in years five and six when the sample is around 17 years old. High-risk middle school lottery winners have a lower (but imprecisely estimated) social cost of arrested crimes and spend statistically significantly fewer days incarcerated in all 3 years for which data are available. This reflects the fact that long prison sentences are much more likely for violent offenders. ${ }^{30}$ Such a large reduction in incarceration suggests that the increase in arrests in later years among lottery winners might be partly driven by the incapacitation of violent felons, who are more likely to be in the group of lottery losers. We can see this with the cumulative incarceration result in the last row. The share of highrisk youth who have been incarcerated for a total of 90 days or more is much greater among those who lost the lottery, and a reduction of about 8 percentage points (over $50 \%$ of the control mean) persists for 7 years after random assignment.

\section{IV.C. Other Outcomes}

A key limitation of this analysis is that I do not observe juvenile crime. This lack of early data could mask big differences in juvenile offending in the early years of the treatment. As an alternative, Table VII shows the effect of winning the lottery on school disciplinary outcomes such as absences and suspensions, as well as test scores and course-taking. Because nearly all of the impacts on crime come from the highest risk youth, I report results for the highest risk quintile only, although the model is estimated with all male members of the sample. The first two rows show

30. In the pooled sample, $30 \%$ of youth with at least one arrest for an index violent crime but no property or drug arrests have spent 180 days or more incarcerated. These figures are only $8 \%$ and $11 \%$ for property and drug arrests, respectively. 


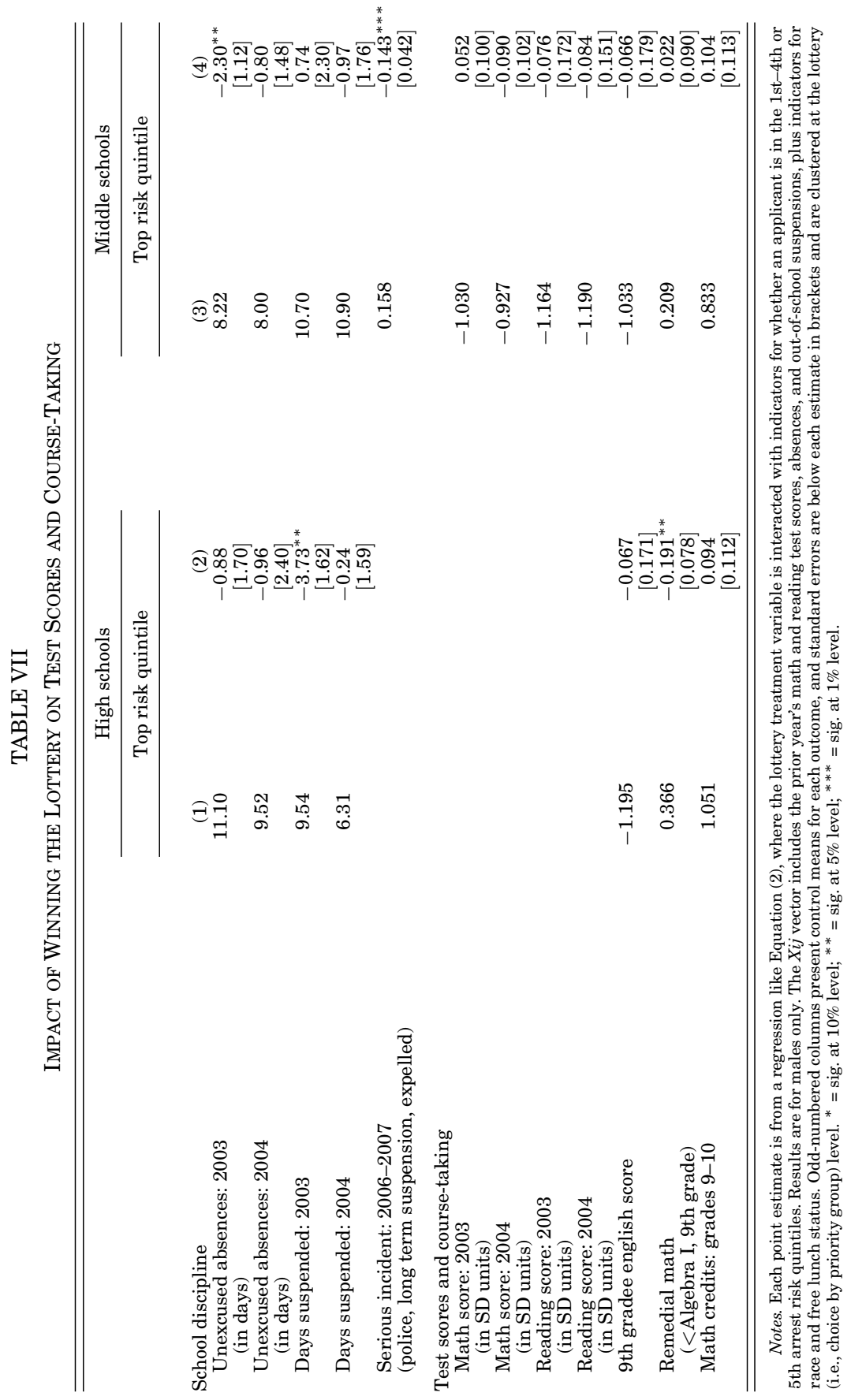


results for unexcused absences in the first 2 school years after the treatment, and the next two rows show the same thing but for outof-school suspensions. Overall, lottery winners in both samples spend slightly more days in school. All four point estimates (2 samples, 2 years) for absences are negative, although only the 2003 middle school results are statistically significant. The effect for high school suspensions in 2003 is relatively large (a reduction of 3.7 from a baseline of 9.5 in the control group), but the other effects are small and statistically insignificant. Finally, I find that middle school lottery winners are less likely to be involved in a disciplinary incident where the punishment was long-term suspension, expulsion, or police involvement. ${ }^{31}$

In contrast to the results for crime and disciplinary outcomes, I find no evidence of test score gains. ${ }^{32}$ Results across various test subjects and grades are imprecise and never distinguishable from 0 , and in some cases I can rule out even modest (i.e., greater than 0.1 standard deviations) gains. Finally, I examine impacts on two measures of course-taking - whether a student was enrolled in remedial math (defined as less than Algebra I by 9th grade, which is the latest year a student can take the exam and graduate on time), and total math credits accumulated on EOC exams in 9 th and 10th grade. High-risk lottery winners in high school are much less likely to be enrolled in remedial math (19 percentage points from a control group baseline of 37\%). However, there is no decrease in remedial math among lottery winners in the middle school sample. The impact on math credits is positive but imprecise in both samples.

Table VIII examines the effect of winning the lottery on enrollment, grade progression, and grade attainment for highrisk youth. The school enrollment measures in the first four rows classify respondents as enrolled if they are present in CMS in the

31. I use a detailed disciplinary incident file maintained by CMS beginning in the 2006-2007 school year. Thus I cannot look at incidents for the high school sample at all or for any of the treatment years in the middle school sample.

32. For the middle school sample, the test score measures are results from standardized math and reading exams administered yearly for grades $3-8$. High schools administer a set of end-of-course (EOC) exams in subjects such as Algebra I, Geometry, Biology, and English. However, they are not taken by all students or even in the same grade in many cases, and so selection into test-taking may compromise interpretation of the results. The one exception is English I, which is taken in ninth grade by almost all students, so I include it as the only high school test score measure. 
TABLE VIII

IMPACT OF WINNING THE LOTTERY ON HIGH SCHOOL ENROLLMENT

\begin{tabular}{|c|c|c|c|c|}
\hline \multirow[b]{3}{*}{ Enrollment } & \multirow{2}{*}{\multicolumn{2}{|c|}{$\frac{\text { High schools }}{\text { Top risk quintile }}$}} & \multirow{2}{*}{\multicolumn{2}{|c|}{$\frac{\text { Middle schools }}{\text { Top risk quintile }}$}} \\
\hline & & & & \\
\hline & (1) & (2) & (3) & (4) \\
\hline In CMS: Grade 9 year & 0.930 & $\begin{array}{c}0.014 \\
{[0.056]}\end{array}$ & 0.767 & $\begin{array}{c}0.032 \\
{[0.054]}\end{array}$ \\
\hline In CMS: Grade 10 year & 0.673 & $\begin{array}{c}-0.023 \\
{[0.082]}\end{array}$ & 0.586 & $\begin{array}{l}0.181^{* * *} \\
{[0.068]}\end{array}$ \\
\hline In CMS: Grade 11 year & 0.541 & $\begin{array}{c}0.052 \\
{[0.073]}\end{array}$ & 0.519 & $\begin{array}{c}0.091 \\
{[0.076]}\end{array}$ \\
\hline In CMS: Grade 12 year & 0.348 & $\begin{array}{c}0.008 \\
{[0.080]}\end{array}$ & 0.376 & $\begin{array}{c}-0.032 \\
{[0.073]}\end{array}$ \\
\hline \multicolumn{5}{|l|}{ Grade progression } \\
\hline "On Track": Grade 9 year & 0.698 & $\begin{array}{c}0.146^{* *} \\
{[0.056]}\end{array}$ & 0.534 & $\begin{array}{c}0.032 \\
{[0.054]}\end{array}$ \\
\hline “On Track": Grade 10 year & 0.345 & $\begin{array}{c}0.133 \\
{[0.084]}\end{array}$ & 0.271 & $\begin{array}{c}0.055 \\
{[0.065]}\end{array}$ \\
\hline "On Track": Grade 11 year & 0.207 & $\begin{array}{c}0.121^{*} \\
{[0.071]}\end{array}$ & 0.233 & $\begin{array}{c}-0.079 \\
{[0.054]}\end{array}$ \\
\hline "On Track": Grade 12 year & 0.163 & $\begin{array}{c}0.030 \\
{[0.071}\end{array}$ & 0.173 & $\begin{array}{c}-0.067 \\
{[0.047]}\end{array}$ \\
\hline \multicolumn{5}{|l|}{ Final status } \\
\hline CMS graduate & 0.272 & $\begin{array}{r}-0.029 \\
{[0.089]}\end{array}$ & 0.105 & $\begin{array}{c}-0.033 \\
{[0.036]}\end{array}$ \\
\hline Still enrolled: 2009 & & & 0.143 & $\begin{array}{c}0.031 \\
{[0.064]}\end{array}$ \\
\hline Verified dropout ( $>9$ th Grade) & 0.272 & $\begin{array}{c}-0.064 \\
{[0.054]}\end{array}$ & 0.226 & $\begin{array}{c}0.103 \\
{[0.065]}\end{array}$ \\
\hline Transfer & 0.207 & $\begin{array}{c}0.098 \\
{[0.083]}\end{array}$ & 0.278 & $\begin{array}{c}-0.066 \\
{[0.054]}\end{array}$ \\
\hline No show & 0.250 & $\begin{array}{c}-0.003 \\
{[0.052]}\end{array}$ & 0.248 & $\begin{array}{r}-0.035 \\
{[0.058]}\end{array}$ \\
\hline
\end{tabular}

Notes. Each point estimate is from a regression like Equation (2), where the lottery treatment variable is interacted with indicators for whether an applicant is in the 1st-4th or 5th arrest risk quintiles. Results are for males only. The $X i j$ vector includes the prior year's math and reading test scores, absences, and out-of-school suspensions, plus indicators for race and free lunch status. Odd-numbered columns present control means for each outcome, and standard errors are below each estimate in brackets and are clustered at the lottery (i.e., choice by priority group) level. The enrollment variables track whether a student is enrolled in any CMS school in the year they would have been in each grade if they were progressing "on time". "On track" is defined as whether a student has advanced at least one grade per year since the lottery and is not enrolled in an alternative school. See the text for a discussion of the final status variables. ${ }^{*}=$ sig. at $10 \%$ level; ${ }^{* *}=$ sig. at $5 \%$ level; ${ }^{* * *}=$ sig. at $1 \%$ level.

year that they would have been in each grade if they progressed "on time." For example, rising sixth-grade lottery applicants would be enrolled in ninth grade in the 2005-2006 school year, so if they are still enrolled in CMS at the end of 2006 they are counted, even if 
they are not in grade 9. High-risk middle school lottery winners are 18 percentage points more likely to be enrolled in CMS in their 10 th-grade year. The effect on 11th-grade enrollment is about half the size (9 percentage points) but imprecisely estimated, and there is no impact on persistence into the 12th-grade year.

Next I measure grade progression by counting students as "on track" if they have advanced at least one grade for every year since the lottery and are not enrolled in an alternative school. The pattern here is exactly the opposite as the results for enrollment. High school lottery winners are more likely to be "on track" for 9 th, 10th, and 11th grade. The estimates are of similar size in absolute terms (between 12 and 14 percentage points) but grow in relative terms, as lottery losers increasingly fall behind or enroll in alternative schools. The effect fades to insignificance by 12 th grade, however. In contrast, there is no effect on grade progression for high-risk middle school lottery winners.

Despite the impacts on enrollment and progression, there is no detectable increase in high school graduation in either sample. Because I am limited to CMS administrative data, it is difficult to distinguish dropouts from subsequent GED recipients or transfers who may have graduated elsewhere ${ }^{33}$ Administrative records are particularly problematic for high-risk youth, who are marginally attached to school and sometimes disappear from CMS well before the legal age of school leaving. ${ }^{34}$ The graduation rate is only about $25 \%$ among high-risk high school students, and currently only about $10 \%$ among middle school students, although some who are still enrolled may subsequently graduate. Additionally, a bit less than $10 \%$ of the middle school sample never appears in any high school grade but subsequently appears in the arrest data. Because any intervention aimed at high school students would miss them altogether, this suggests that high school might be too late for the highest risk youth.

33. Students who stop showing up for school are counted as either dropouts, transfers, or no-shows, but there is considerable uncertainty across those categories. First, students are coded as dropouts only at age 16 and above. Second, transfers (even out-of-state) often show up subsequently in the Mecklenburg County arrest data.

34. To illustrate the unreliability of exit coding, I calculate the average social cost of crimes for members of the sample who are recorded as transfers versus dropouts. Strikingly, despite the fact that some of the transfers are "real," the social cost of crime among them averages about $\$ 11,347$, compared with $\$ 18,584$ for verified dropouts. 


\section{Discussion AND Policy ImPLiCATIONS}

\section{V.A. Mechanisms: School Quality or Peer Effects?}

Overall, I find that winning the lottery to attend a first choice school has large impact on crime for high-risk youth. In this section I discuss several possible explanations for the results. One is that winning the lottery entails longer bus rides to and from school, incapacitating youth during high-crime hours. More generally, winning the lottery could prevent crime by removing high-risk youth from "criminogenic" peers or neighborhoods (e.g., Sampson, Morenoff, and Gannon-Rowley 2002; Kling, Ludwig, and Katz 2005). Prominent models of criminal contagion treat individual crime as a function of contemporaneous exposure to crime-prone peers (Sah 1991; Glaeser, Sacerdote, and Scheinkman 1996; Ludwig and Kling 2007). However, both incapacitation and contagion explanations would predict a strong initial effect that fades over time. If, for example, drug market activity is concentrated within a few schools, we might expect large differences in criminality in the high school years that diminish as enrollment in the treatment school ends and lottery winners and losers return to the same neighborhoods. I conclude that there is little support for these hypotheses since they do not fit the pattern of results over time in Tables V and VI. It is also possible that attending a better school decreases the probability of arrest conditional on crime. ${ }^{35}$

One candidate hypothesis is that the reduction in crime comes from the human capital returns to attending a higher quality school. In a human capital framework, increased school quality would raise the marginal productivity of investment in schooling. Youth who are given the opportunity to attend a better school would stay enrolled longer and acquire more skills, which would translate into a higher expected wage in the labor market. The effect of winning the lottery is largest at ages when most youth are mixing schooling, crime and work in some combination (Grogger 1998). Higher wages raise the opportunity cost of crime and incarceration, lowering the optimal amount of crime committed (Lochner 2004). To the extent that skills acquired in school have

35. Although I cannot provide any direct evidence on this, Lochner and Moretti (2004) find that the relationship between schooling and incarceration in the Census is similar to the relationship between schooling and self-reported crime, at least for white males. This suggests that higher levels of schooling do not greatly alter the probability of arrest conditional on crime. 
a persistent effect on wages, reductions in crime would also be persistent. In both samples combined, about $80 \%$ of students have already dropped out of school by the time they are arrested for their first felony. Furthermore, even among the remaining $20 \%$, students with arrest records are often absent and/or suspended for long stretches of time before an arrest occurs. Thus it is plausible that keeping students enrolled longer, or maintaining a stronger attachment to school, reduces the overall amount of crime committed by delaying the onset of criminality through the peak period of offending (Moffitt 1993; Nagin and Tremblay 1999).

I test the school quality hypothesis by applying the changes in enrollment in Table VIII to my best estimates of their marginal impact on crime. Although the enrollment impacts in Table VIII appear relatively weak, evidence from changes in compulsory schooling laws suggests that even one additional year of education at a relatively low level can have a large impact on crime (Lochner and Moretti 2004; Machin, Marie, and Vujic 2011). Using the full nonlottery sample, I estimate a regression of the trimmed social cost of crime measure on a full set of dummy variables for whether students graduated and were enrolled and/or "on time" in grades 9-12, a set of covariates including a third-order polynomial in the arrest prediction, and 2002 school fixed effects. I then multiply those coefficients by the enrollment impacts in Table VIII and back out the share of the total reduction in the social cost of crime that can be explained by school enrollment.

For these regression coefficients to be unbiased estimates of the marginal impact of an additional year of enrollment, it must be the case that I have controlled for all important determinants of crime that are correlated with enrollment and that the impacts in the nonlottery sample hold for lottery applicants as well. Although both of these assumptions are generous, the results from this speculative, back-of-the envelope calculation are informative. I find that changes in enrollment can potentially explain about $45 \%$ of the impact in the high school sample, but only about $10 \%$ in the middle school sample. This is largely because "on time" enrollment is a more important predictor of future crime than simply being present in school, after adjusting for individual characteristics and home school fixed effects.

Alternatively, peer networks formed in middle or high school could have a persistent influence on adult criminality without affecting human capital or wages directly. Although there is much evidence that social network formation is particularly important 
in the teenage years (e.g., Evans, Oates, and Schwab 1992; Haynie 2001; Sacerdote 2001), there is little available evidence on the persistence into adulthood of criminal ties formed in adolescence. I test the hypothesis that increased exposure to crime-prone peers in school-age years leads to more crime in adulthood. Similar to the enrollment calculation, I multiply the change in lottery winners' peer criminality estimated in Table II by my best estimate of the impact of peer criminality on adult crime. Using the nonlottery sample, I regress crime outcomes on the predicted criminality of a student's peers, a set of covariates including a third-order polynomial in the student's individual arrest prediction, and prior year school fixed effects. I also include in the regression a quadratic in average peer criminality, to see whether concentrations of high-risk peers have a nonlinear impact on students' own crime. Finally, following Hoxby and Weingarth (2005) and Imberman, Kugler, and Sacerdote (2011), I allow the impact of peer criminality to vary with the student's own risk quintile.

The results are in Table IX. Column (1) displays the impact of peer criminality on high school students, column (2) adds a quadratic in peer criminality, and column (3) allows the effect to vary by students' own risk quintile. Columns (4) through (6) repeat this pattern for the middle school sample. The top half of the table presents results for index violent crimes, and the bottom half presents results for drug felonies. ${ }^{36}$ The patterns are very different in the two samples and for the two types of crime. I find very weak evidence for peer effects on violent crimes in the high school sample. This may be due in part to the high rate of early dropout among violent felons. However, crimeprone middle school peers increase own crime, and the impact is much larger and statistically significant for youth in the top risk quintile.

The impact for drug felonies, however, is much larger in the high school sample and is nearly identical across risk quintiles. Multiplying these estimates for the top risk quintile by the changes in predicted criminality in Table III, I estimate that changes in peers can explain only $9 \%$ of the impact on violent arrests in the middle school sample and $2 \%$ of the impact on drug

36. The results for the social cost of crime outcome are very similar to those for index violent crimes but are much less precisely estimated. I present the drug felony results as well because the pattern is quite different and because the crime reduction in the high school sample is driven by reductions in drug felonies. 


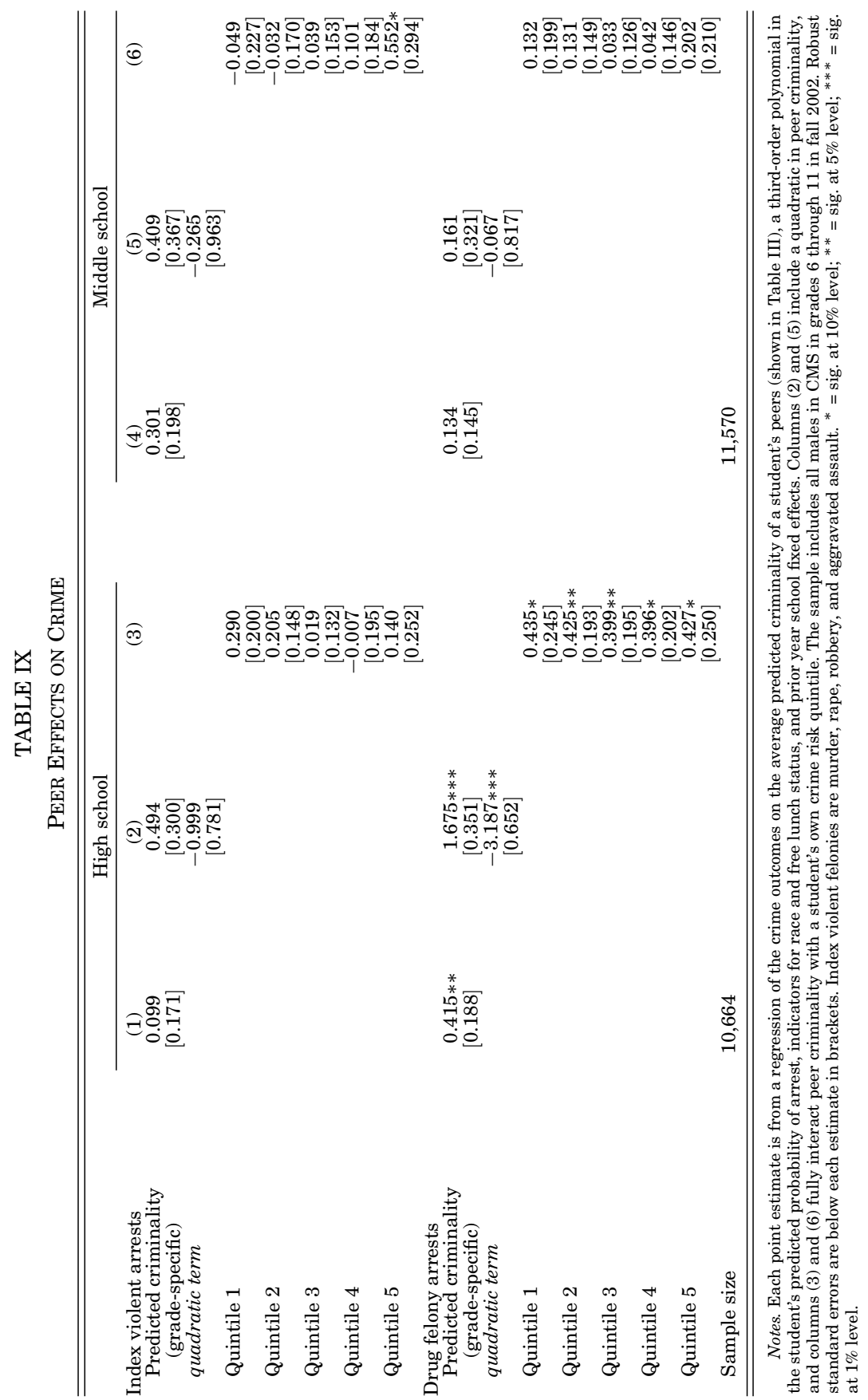


arrests in the high school sample. ${ }^{37}$ Moreover, since the quadratic terms in columns (2) and (5) are all negative, looking only at youth in the most crime-prone schools would not increase the share explained by peers.

The pattern of impacts by risk quintile in columns (3) and (6) has interesting implications for the aggregate impact of school choice. The results suggest that at least in middle school, concentrating crime-prone youth in the same place may lead to more crime in the aggregate. This matches results from other studies which suggest that concentrations of disruptive children increase overall misbehavior (Cook and Ludwig 2005; Carrell and Hoekstra 2010; Imberman, Kugler, and Sacerdote 2011). As we saw in Figure I, the net impact of school choice in CMS was to spread high-risk youth across many more schools than if students were only allowed to attend schools in their neighborhood zone. This implies that school choice may have decreased total violent crime among middle school youth, even after considering the possible negative externality imposed by these youth on their new peers. For drug felonies, however, there is no evidence that resorting of students impacts aggregate levels of drug crime, since the impact of an increase in crime-prone peers is roughly constant across risk quintiles.

These back-of-the envelope calculations seem to suggest that peer effects are not large enough to explain much of the impact of winning the lottery on crime. However, it is important to remember that lottery applicants are a self-selected sample. It is very plausible that high-risk lottery applicants are in the sample because they (or more likely, their families) are trying to escape the negative influence of particular peers in their neighborhood school. In that sense the impact of winning the lottery could be driven by match-specific peer effects that would not show up in the calculations above. This would also explain why significant numbers of rising seventh and eighth graders applied to the lottery, and why high-risk lottery losers were less likely to return to their neighborhood schools than lottery losers in the first through fourth risk quintiles.

Given this concern and the loose nature of the calculations, we should interpret the estimated share of the impact explained

37. Part of the difference is explained by the fact that middle school youth also attend high school with less crime-prone peers, but even without adding high school peer effects the share explained in the middle school sample is about three times higher. 
by enrollment impacts (45\% in high school and $10 \%$ in middle school) and peers (2\% in high school and $9 \%$ in middle school) with an abundance of caution. Rather than interpreting the numbers literally, we could surmise that the human capital/school quality mechanism is more important for high school lottery winners, whereas peer effects are more important in middle school. This matches some of the evidence from Table III. High school lottery winners experienced larger gains in measured teacher quality and revealed preference and were more likely to attend a magnet school. Furthermore, the most commonly chosen school in the high school sample was a magnet career academy, which has been shown to increase earnings among minority males without improving test scores or the likelihood of graduation (Kemple and Willner 2008). In contrast, much more of the gain in measured school quality comes from peer test scores and demographics in the middle school sample.

\section{V.B. Policy Simulation and Welfare Implications}

Because criminal involvement can be predicted using information that is readily available to the school district, a lottery mechanism that gives priority to high-risk youth could reduce crime more effectively. To quantify the benefits of targeting, I simulate the lottery and resulting distribution of students to schools under two alternative assignment rules. First, I assign open slots to the highest risk students (based on the prediction generated in Section III.A.) in descending order, for each lottery. While such an allocation system would be controversial, it is feasible since all the covariates are available to the school district. Second, I simulate a simple lottery with no priority groupings, similar to the decentralized lotteries conducted by many U.S. charter schools. The CMS lottery system assigned a "priority boost" to FRPL students who applied to schools with a low fraction of FRPL students in the previous year. As a consequence, many poor (and high crime risk) students were automatically admitted to schools when other students had to win the lottery (or, in some cases, only FRPL students could be admitted, and no other students were admitted).

For both assignment rules, I simulate the lottery 500 times and calculate the new expected distribution of students to schools. In the last step, I use the original parameter values from the estimation of Equation (2) for the social cost of crime outcome. This calculation makes some important assumptions. First, it assumes 
that students' choices were not strategic, and thus they would not have changed their preferences if the assignment rules changed. Second, it assumes that the relationship I estimate between crime risk and the social cost outcome is valid out of sample. Finally, it assumes that there are no differential spillover effects from lottery winners to their schoolmates under each scenario.

I estimate that if slots in oversubscribed schools were allocated to the highest risk students, the social cost of crime would fall by an additional $27 \%$ relative to the actual CMS assignment mechanism. A more realistic form of targeting is the method actually pursued by CMS-a "priority boost" for economically disadvantaged students. I estimate that this policy choice lowered the social cost of crime by about $12 \%$, relative to a simple lottery with no preferential treatment. Most of the difference comes from changes in the middle school lottery, for two reasons. First, the effect is more strongly increasing in crime risk for the middle school lottery than for the high school lottery (see Figures II and III). Second, there is much less sorting across choices at the middle school level, so there are many low- and high-risk students applying to the same schools.

CMS chose to implement an open enrollment school choice plan as an alternative to a traditional neighborhood schools model. They expanded capacity at schools where high demand was anticipated, including magnet schools that were located in the inner city. These schools increased yearly enrollment substantially and were in many cases still oversubscribed. Many low-performing schools, on the other hand, experienced large reductions in enrollment-by as much as $50 \%$ in some cases. Thus, relative to a pure neighborhood schools model, the net effect of open enrollment was to increase access to magnet and highly demanded schools for youth who would not otherwise be able to enroll. This strong demand response means that the treatment is not just a transfer from losers to winners and could represent a real welfare gain.

All the results so far have been ITT estimates of the effect of winning the lottery. However, we can also calculate LATEs for youth who comply with their lottery status, using the lottery as an instrument for enrollment. ${ }^{38}$ Since the average "first-stage" effect

38. The IV estimates are only valid if the monotonicity assumption ("no defiers"-i.e., no applicant would have enrolled if they lost or not enrolled if they won) holds (Angrist, Imbens, and Rubin 1996). The group of compliers is a latent type, since we cannot directly observe who among the complier lottery losers would 
was around 0.55 , the LATEs are a bit less than double the ITT estimates for each outcome. Following Hoxby and Murarka (2009) and Abdulkadiroglu et al. (2011), I can also calculate the per-year effect of enrollment in a first choice school. This is particularly large for high-risk youth-each year of enrollment saves society over $\$ 55,000$ in criminal victimization costs for arrested crimes. Finally, I use the lottery as an instrument for the quality of the school attended by applicants in fall 2002. I calculate the average of the four normalized school quality measures in Table II. Assuming that all the treatment effect operates through measured school quality, a one standard deviation increase in school quality leads to a reduction in the social cost of arrested crimes of about $\$ 23,000$ per applicant and about $\$ 110,000$ per high-risk youth.

\section{CONCLUSION}

In this article I estimate the longer-term impact on adult crime of winning an admissions lottery to attend a better middle or high school. I find that winning the lottery greatly reduces crime, and the impact is concentrated among the highest risk youth in the sample. The impacts persist beyond the years of school enrollment, 7 years after random assignment. The findings suggest that schools may be a particularly important setting for the prevention of future crime. Many high-risk youth in the sample drop out of school at a very young age and are incarcerated for serious crimes prior to the age of high school graduation. For these youth on the margins of society, public schools may present the best opportunity to intervene.

The end of busing and the implementation of open enrollment in CMS was a significant policy change. The four neighborhood high schools to which most of the lottery applicants were assigned lost over $20 \%$ of their enrollment in a single year. In subsequent years, two of these schools were restructured as magnet schools that offered a series of specialized programs in a small school setting. Similarly, two middle schools with significant student out-migration were subsequently closed. In this way, the open enrollment policy sent a strong signal of parental demand to CMS

have enrolled if they had won (and vice versa for winners). Empirically, observed compliers are drawn from the middle of the distribution of arrest risk relative to the lottery loser "always-takers" and the lottery winner "never-takers." 
that may have resulted in shutting down or restructuring lowperforming schools. The No Child Left Behind Act of 2001 included a provision that allowed parents to transfer students from "persistently dangerous" public schools, but many states have set the legal threshold so high that very few schools qualify. The results here suggest that to the extent that low-quality schools are also persistently dangerous, allowing students to leave them for a better school might benefit individual students as well as society as a whole.

\section{HARVARD UNIVERSITY}

\section{SUPPLEMENTARY MATERIAL}

An Online Appendix for this article can be found at QJE online (qje.oxfordjournals.org).

\section{REFERENCES}

Abdulkadiroglu, Atila, Joshua D. Angrist, Susan M. Dynarski, Thomas J. Kane, and Parag Pathak, "Accountability and Flexibility in Public Schools: Evidence from Boston's Charters and Pilots," Quarterly Journal of Economics (2011), forthcoming.

Abdulkadiroglu, Atila, and Tayfun Somnez, "School Choice: A Mechanism Design Approach," American Economic Review, 93 (2003), 729-747.

Angrist, Joshua D., Susan M. Dynarski, Thomas J. Kane, Parag A. Pathak, and Christopher R. Walters, "Who Benefits from KIPP?," NBER Working Paper w15740, 2010.

Angrist, Joshua D., Guido W. Imbens, and Donald B. Rubin, "Identification of Causal Effects Using Instrumental Variables," Journal of the American Statistical Association, 91 (1996), 444-455.

Becker, Gary S., "Crime and Punishment: An Economic Approach," Journal of Political Economy, 76 (1968), 169-217.

Belfield, Clive R., Milagros Nores, Steve Barnett, and Lawrence Schweinhart, "The High/Scope Perry Preschool Program: Cost Benefit Analysis Using Data from the Age-40 Followup," Journal of Human Resources, 41 (2006), 162-190.

Bhattacharya, Debopam, and Pascaline Dupas, "Inferring Welfare Maximizing Treatment Assignment under Budget Constraints," NBER Working Paper w14447, 2008.

Carrell, Scott E., and Mark L. Hoekstra, "Externalities in the Classroom: How Domestic Violence Harms Everyone's Kids," American Economic Journal: Applied Economics, 2 (2010), 211-228.

Cook, Philip J., Denise C. Gottfredson, and Chongmin Na, "School Crime Control and Prevention," Crime and Justice, 39 (2010), 313-440.

Cook, Philip J., and Jens Ludwig, "Assigning Deviant Youth to Minimize Total Harm," NBER Working Paper w11390, 2005.

Cullen, Julie Berry, Brian A. Jacob, and Steven D. Levitt, "The Effect of School Choice on Participants: Evidence from Randomized Lotteries," Econometrica, 74 (2006), 1191-1230.

Currie, Janet, and Duncan Thomas, "Early Test Scores, School Quality and SES: Longrun Effects on Wage and Employment Outcomes," Research in Labor Economics, 20 (2001), 103-132. 
Deming, David, "Early Childhood Intervention and Life-Cycle Skill Development: Evidence from Head Start," American Economic Journal: Applied Economics, 1 (2009), 111-134.

Dobbie, Will, and Roland G. Fryer, "Are High-Quality Schools Enough to Increase Achievement among the Poor? Evidence from the Harlem Children's Zone," American Economic Journal: Applied Economics, 3 (2011), 158-187.

Donohue, John J., and Peter Siegelman, "Allocating Resources among Prisons and Social Programs in the Battle against Crime," Journal of Legal Studies, 27 (1998), 1-43.

Ehrlich, Isaac, "Participation in Illegitimate Activities: A Theoretical and Empirical Investigation," Journal of Political Economy, 81 (1973), 521-565.

Epple, Dennis, and Richard E. Romano, "Competition between Private and Public Schools, Vouchers, and Peer-Group Effects," American Economic Review, 88 (1998), 33-62.

Evans, William N., Wallace E. Oates, and Robert M. Schwab, "Measuring Peer Group Effects: A Study of Teenage Behavior," Journal of Political Economy, 100 (1992), 966-991.

Farrington, David P., Bernard Gallagher, Lynda Morley, Raymond St. Ledger, and Donald J. West, "Unemployment, School Leaving, and Crime," British Journal of Criminology, 26 (1986), 335-356.

Figlio, David N., "Testing, Crime and Punishment," Journal of Public Economics, 90 (2006), 837-851.

Figlio, David N., and Joshua Winicki, "Food for Thought: The Effects of School Accountability Plans on School Nutrition," Journal of Public Economics 89 (2005), 381-394.

Freeman, Richard B., "Crime and the Job Market," NBER Working Paper w4910, 1994.

Glaeser, Edward L., Bruce Sacerdote, and Jose Scheinkman, "Crime and Social Interactions," Quarterly Journal of Economics, 111 (1996), 507-548.

Gould, Eric D., Victor Lavy, and M. Daniele Paserman, "Immigrating to Opportunity: Estimating the Effect of School Quality Using a Natural Experiment on Ethiopians in Israel," Quarterly Journal of Economics, 119 (2004), $489-526$.

Grogger, Jeffrey, "Market Wages and Youth Crime," Journal of Labor Economics, 16 (1998), 756-791.

Harlow, Caroline W, Education and Correctional Populations, Bureau of Justice Statistics Special Report (Washington, DC: Bureau of Justice, 2003).

Hastings, Justine S., Thomas J. Kane, and Douglas O. Staiger, "Heterogeneous Preferences and the Efficacy of Public School Choice," unpublished working paper, 2008.

Haynie, Dana L., "Delinquent Peers Revisited: Does Network Structure Matter?," American Journal of Sociology, 106 (2001), 1013-1057.

Hoxby, Caroline M., "School Choice and School Productivity: Could School Choice Be a Tide that Lifts all Boats?," inThe Economics of School Choice, ed. Caroline M. Hoxby (Chicago: University of Chicago Press, 2003).

Hoxby, Caroline M., and Gretchen Weingarth, "Taking Race out of the Equation: School Reassignment and the Structure of Peer Effects," unpublished working paper, 2005.

Hoxby, Caroline M., and Sonali Murarka, "Charter Schools in New York City: Who Enrolls and How They Affect Their Students' Achievement," NBER Working Paper w14852, 2009.

Imberman, Scott A.,, Adriana D. Kugler, and Bruce Sacerdote, "Katrina's Children: Evidence on the Structure of Peer Effects from Hurricane Evacuees," American Economic Review, forthcoming.

Jackson, C. Kirabo, "Student Demographics, Teacher Sorting, and Teacher Quality: Evidence from the End of School Desegregation," Journal of Labor Economics, 27 (2009), 213-256.

Jacob, Brian A., "Public Housing, Housing Vouchers, and Student Achievement: Evidence from Public Housing Demolitions in Chicago," American Economic Review, 94 (2004), 233-258. 
, "Accountability, Incentives and Behavior: The Impact of High-Stakes Testing in the Chicago Public Schools," Journal of Public Economics, 89 (2005), 761-796.

Jacob, Brian A., and Lars Lefgren, "Are Idle Hands the Devil's Workshop? Incapacitation, Concentration, and Juvenile Crime," American Economic Review, 93 (2003), 1560-1577.

Jacob, Brian A., and Steven D. Levitt, "Rotten Apples: An Investigation of the Prevalence and Predictors of Teacher Cheating," Quarterly Journal of Economics, 118 (2003), 843-877.

Jencks, Christopher S., and Meredith Phillips, "Aptitude or Achievement: Why Do Test Scores Predict Educational Attainment and Earnings?," in Earning and Learning: How Schools Matter, ed. Susan Mayer and Paul Peterson (Washington, DC: Brookings Institution Press, 1999).

Kemple, James J., and Cynthia J. Willner, Career Academies: Long-Term Impacts on Labor Market Outcomes, Educational Attainment and Transitions to Adulthood. (New York: MDRC, 2008).

Kling, Jeffrey R., Jens Ludwig, and Lawrence F. Katz, "Neighborhood Effects on Crimefor Female and Male Youth: Evidence from a Randomized Housing Voucher Experiment," Quarterly Journal of Economics, 120 (2005), 87-130.

Krueger, Alan B., and Diane M. Whitmore, "The Effect of Attending a Small Class in the Early Grades on College-Test Taking and Middle School Test Results: Evidence from Project STAR," Economic Journal 111 (2001), 1-28.

Lankford, Hamilton, Susanna Loeb, and JamesWyckoff, "Teacher Sorting and the Plight of Urban Schools: A Descriptive Analysis," Educational Evaluation and Policy Analysis, 24 (2002), 37-62.

Lavy, Victor, "Effects of Free Choice among Public Schools," Review of Economic Studies, 77 (2010), 1164-1191.

Lee, David, and Justin McCrary, "Crime, Punishment, and Myopia," NBER Working Paper w11491, 2005.

Levitt, Steven D., and Lance Lochner, "The Determinants of Juvenile Crime," in Risky Behavior among Youths: An Economic Analysis, ed. Jonathan Gruber (Chicago: University of Chicago Press, 2001).

Lochner, Lance, "Education, Work, and Crime: A Human Capital Approach," International Economic Review, 45 (2004), 811-843.

Lochner, Lance, and Enrico Moretti, "The Effect of Education on Crime: Evidence from Prison Inmates, Arrests, and Self-reports," American Economic Review, 94 (2004), 155-189.

Ludwig, Jens, Greg J. Duncan, and Paul Hirschfield, "Urban Poverty and Juvenile Crime: Evidence from a Randomized Housing-Mobility Experiment," Quarterly Journal of Economics, 116 (2001), 655-679.

Ludwig, Jens, and Jeffrey R. Kling, "Is Crime Contagious?," Journal of Law and Economics, 50 (2007), 491-518.

Machin, Stephen, Olivier Marie, and Suncica Vujic, "The Crime Reducing Effect of Education," Economic Journal, 121 (2011), 463-484

Miller, Ted R., Mark A. Cohen, and Brian Wiersema, "Victim Costs and Consequences: A New Look," National Institute of Justice Research Report NCJ$155282,1996$.

Moffitt, Terrie E., "Adolescence-Limited and Life-Course-Persistent Antisocial Behavior: A Developmental Taxonomy," Psychological Review, 100 (1993), 674.

Murnane, Richard J., "Educating Urban Children,” NBER Working Paper w13791, 2008 .

Murnane, Richard J., John B. Willett, and Frank Levy, "The Growing Importance of Cognitive Skills in Wage Determination," Review of Economics and Statistics, 77 (1995), 251-266.

Nagin, Daniel, and Richard E. Tremblay, "Trajectories of Boys' Physical Aggression, Opposition, and Hyperactivity on the Path to Physically Violent and Nonviolent Juvenile Delinquency," Child Development, 70 (1999), 1181-1196.

Oreopoulos, Philip, "Estimating Average and Local Average Treatment Effects of Education when Compulsory Schooling Laws Really Matter," American Economic Review, 96 (2006), 152-175. 
Pettit, Becky, and Bruce Western, "Mass Imprisonment and the Life Course: Race and Class Inequality in US Incarceration," American Sociological Review, 69 (2004), 151-169.

Raphael, Steven, and Melissa Sills, "Urban Crime, Race, and the Criminal Justice System in the United States," in A Companion to Urban Economics, ed. Richard J. Arnott and Daniel P. McMillen (Oxford: Blackwell Publishing, 2007).

Sacerdote, Bruce, "Peer Effects with Random Assignment: Results for Dartmouth Roommates," Quarterly Journal of Economics, 116 (2001), 681-704.

Sah, Raaj K., "Social Osmosis and Patterns of Crime," Journal of Political Economy, 99 (1991), 1272-1295.

Sampson, Robert J., and John H. Laub, "Life-Course Desisters: Trajectories of Crime among Delinquent Boys Followed to Age 70," Criminology, 41 (2003), $555-592$.

Sampson, Robert J., Jeffrey D. Morenoff, and Thomas Gannon-Rowley, "Assessing 'Neighborhood Effects': Social Processes and New Directions in Research," Annual Review of Sociology, 28 (2002), 443-478.

Sampson, Robert J., Stephen W. Raudenbush, and Felton Earls, "Neighborhoods and Violent Crime: A Multilevel Study of Collective Efficacy," Science, 277 (1997), 918-924.

Sanbonmatsu, Lisa, Jeffrey R. Kling, Greg J. Duncan, and Jeanne Brooks-Gunn, "Neighborhoods and Academic Achievement: Results from the Moving to Opportunity Experiment," Journal of Human Resources, 41 (2006), 649-691.

Sum, Andrew, Ishwar Khatiwada, Joseph McLaughlin, and Shelia Palma, "The Consequences of Dropping Out of High School," Technical Report, Center for Labor Market Studies, Northeastern University, 2009.

Weiner, David A., Byron Lutz, and Jens Ludwig, "The Effects of School Desegregation on Crime," NBER Working Paper w15380, 2009.

Wolfgang, Marvin E., Robert M. Figlio, and Torstein Sellin, Delinquency in a Birth Cohort (Chicago: University of Chicago Press, 1987). 